\title{
A review of the surface heat transfer coefficients of radiant heating and cooling systems
}

Shinoda, Jun; Kazanci, Ongun Berk; Tanabe, Shin-ichi; Olesen, Bjarne W.

Published in:

Building and Environment

Link to article, DOI:

10.1016/j.buildenv.2019.05.034

Publication date:

2019

Document Version

Peer reviewed version

Link back to DTU Orbit

Citation (APA):

Shinoda, J., Kazanci, O. B., Tanabe, S., \& Olesen, B. W. (2019). A review of the surface heat transfer coefficients of radiant heating and cooling systems. Building and Environment, 159, [106156].

https://doi.org/10.1016/j.buildenv.2019.05.034

\section{General rights}

Copyright and moral rights for the publications made accessible in the public portal are retained by the authors and/or other copyright owners and it is a condition of accessing publications that users recognise and abide by the legal requirements associated with these rights.

- Users may download and print one copy of any publication from the public portal for the purpose of private study or research.

- You may not further distribute the material or use it for any profit-making activity or commercial gain

- You may freely distribute the URL identifying the publication in the public portal 


\section{Accepted Manuscript}

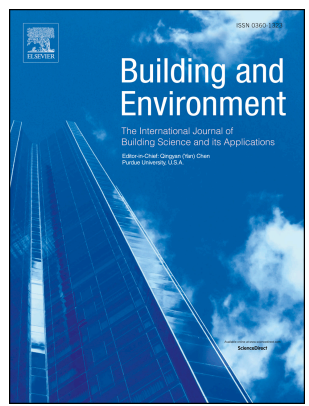

A review of the surface heat transfer coefficients of radiant heating and cooling systems

Jun Shinoda, Ongun B. Kazanci, Shin-ichi Tanabe, Bjarne W. Olesen

PII: $\quad$ S0360-1323(19)30360-9

DOI: $\quad$ https://doi.org/10.1016/j.buildenv.2019.05.034

Reference: BAE 6156

To appear in: Building and Environment

Received Date: 22 March 2019

Revised Date: 9 May 2019

Accepted Date: 16 May 2019

Please cite this article as: Shinoda J, Kazanci OB, Tanabe S-i, Olesen BW, A review of the surface heat transfer coefficients of radiant heating and cooling systems, Building and Environment (2019), doi: https://doi.org/10.1016/j.buildenv.2019.05.034.

This is a PDF file of an unedited manuscript that has been accepted for publication. As a service to our customers we are providing this early version of the manuscript. The manuscript will undergo copyediting, typesetting, and review of the resulting proof before it is published in its final form. Please note that during the production process errors may be discovered which could affect the content, and all legal disclaimers that apply to the journal pertain. 


\section{ACCEPTED MANUSCRIPT}

A Review of the Surface Heat Transfer Coefficients of Radiant Heating and Cooling Systems

西

$$
\text { Jun Shinoda }^{\mathrm{a}, \mathrm{b}^{*} \text {, Ongun B. Kazanci }}{ }^{\mathrm{b}} \text {, Shin-ichi Tanabe }{ }^{\mathrm{a}} \text {, Bjarne W. Olesen }{ }^{\mathrm{b}}
$$

${ }^{\text {a }}$ Department of Architecture, Waseda University, Tokyo 169-8555, Japan

b International Centre for Indoor Environment and Energy, Department of Civil Engineering, Technical University of Denmark, 2800 Kgs. Lyngby, Denmark

* Corresponding author. E-mail address: shinoda@tanabe.arch.waseda.ac.jp

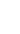

\section{Abstract}

Heat transfer coefficients are often used to describe the thermal behavior of radiant systems in buildings and how they transfer heat between their cooled/heated surfaces and the room. In addition to current standards, several studies have been conducted to determine such heat transfer coefficients by means of experiments and simulations. Inconsistency is evident in the values and expressions derived for this purpose. The present study investigated possible sources of discrepancy in an extensive literature review of articles, standards and guidelines that focus on the heat transfer coefficients of cooled/heated surfaces. Measurement data provided by different authors were analyzed to compare both the amount of heat transfer and the estimated heat transfer coefficients. These estimated values and expressions were used to predict the measured data reported in other articles, to examine their accuracy. Larger deviations and prediction errors were found in the total and convective heat transfer values than in radiant heat transfer, which had a range of errors within $\pm 20 \%$ throughout the literature. The major sources of error were shown to be the calculation procedure for each heat transfer mechanism, the choice of reference temperature and its 
measurement height and position, and room dimensions. It is suggested that heat transfer coefficients should be chosen by matching the calculation/measurement conditions in which they were obtained to the purpose and conditions in which they will be applied.

Keywords: Radiant heating and cooling; surface heat transfer coefficient; reference temperature;

$$
\text { measurement conditions; radiation; convection }
$$

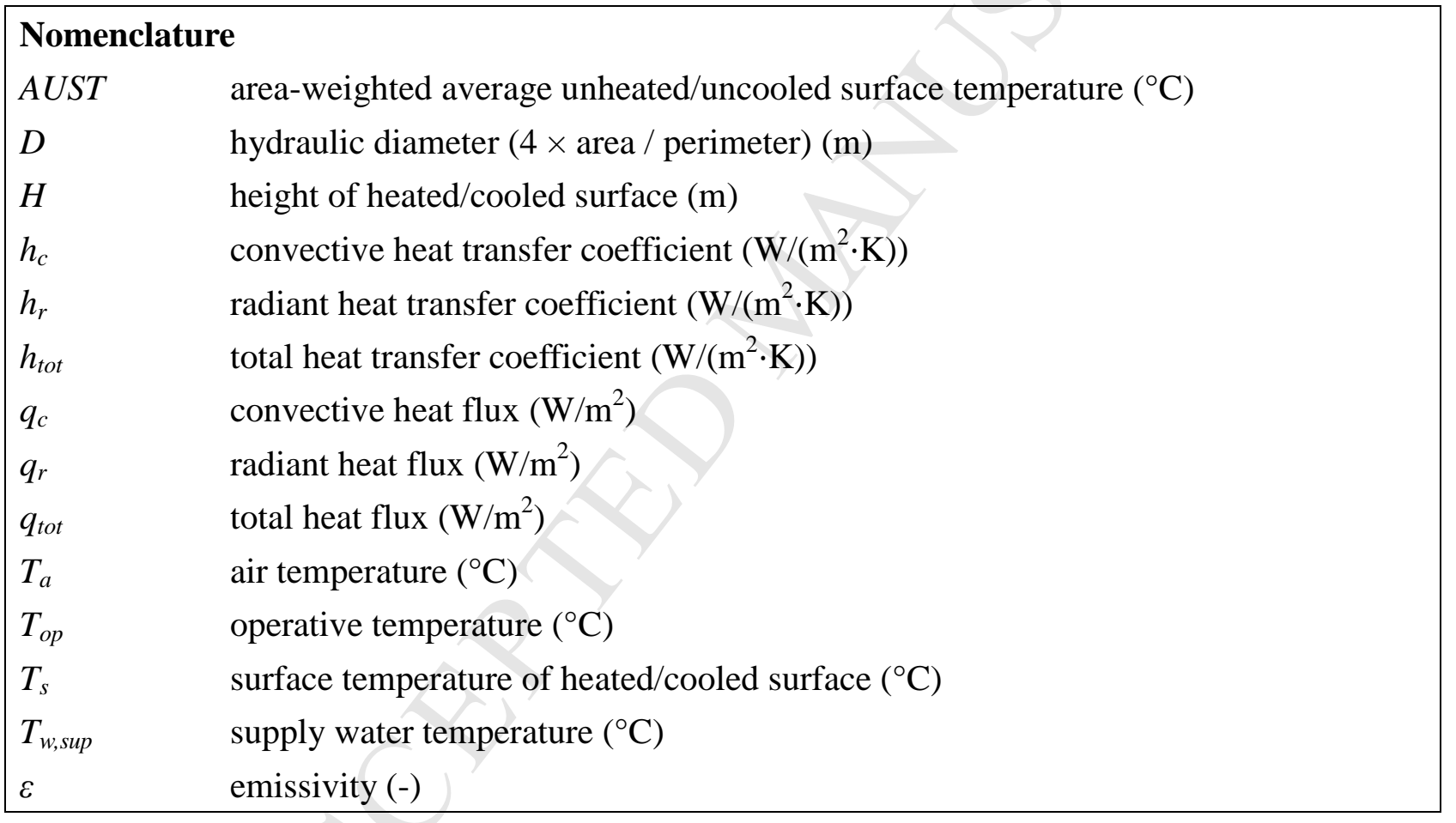


Radiant systems are now commonly used as a comfortable and energy-efficient heating and cooling alternative in buildings in many countries. The heat transfer of radiant systems differs from that of conventional all-air systems in that cooling/heating is provided by both radiation and convection from a cooled/heated surface. In order to quantify the heat transfer between the radiant surface and the room, heat transfer coefficients are often used. They are used in calculations regarding the thermal behavior of radiant systems, such as load calculation and dimensioning. The radiant surface serves as the boundary between the room-side and the system-side (mechanical system) so being able to quantify the heat transfer process at the surface is crucial for the whole design of radiant systems.

In general, radiant and convective heat transfer coefficients, or a combination of the two (total heat transfer coefficients) are used. Radiation and convection are physical processes, where radiation is the heat transfer between surfaces, while convection takes place between a surface and air (or other other surfaces within the room, while convective heat transfer coefficients describe the heat transfer between the radiant surface and air. The convective heat transfer may be driven either by natural convection (buoyancy) or forced convection. When both natural and forced convection take place, it is referred to as mixed convection. To simplify calculations, the total heat transfer coefficient may be used to estimate the combination of the radiant and convective heat transfer from a single value. 


\section{ACCEPTED MANUSCRIPT} 2 in the value.

4 Numerous investigations of heat transfer coefficients have been carried out in previous studies,

In this case, however, it is not clear as to which type of convective heat transfer is implicitly present resulting in many different suggested values. Literature reviews of suggested values [1] and convective heat transfer coefficients $[2,3]$ have been conducted, but it remains uncertain as to which value should be used, or what causes the differences in the first place. It must be emphasized that in either calculations or simulations, the values assumed for heat transfer coefficients greatly influence the resulting heat flux, indoor environment, energy use, etc., as it defines the thermal behavior of the surface that separates the room-side and system-side of the radiant system. The validity of the values assumed depends on the conditions under which they were obtained and the conditions under which they will be used, as they will affect their precision in predicting the heat flux to and from the radiant surface.

This study reports a literature review of the heat transfer coefficients derived specifically for radiant cooling and heating systems, with an emphasis on the measurement conditions and setup used to acquire the data from which they were estimated. Coefficients for total, radiant, and natural convective heat transfer were included in the review, excluding mixed and forced convection due to the complexity of parameters and measurement conditions. The relevant parameters affecting each type of heat transfer and the sources of any discrepancies were investigated. The most urgent topics 
for further research were identified.

\section{Review Method}

In order to gather articles pertaining to the topic of this paper, the Science Direct database was used.

The terms "radiant" (so that terms such as "radiant system" or "radiant cooling/heating" would also be included) and "heat transfer coefficient" were used in the search. The relevance of the articles was determined by the title, abstract and conclusions of each article. Any relevant articles found in the references that were not covered by the Science Direct database (such as ASHRAE Transactions) were searched in other databases such as Techstreet Enterprise and Scopus. Articles were selected from the following journals: Applied Thermal Engineering, ASHRAE Transactions, Building and Environment, Energy and Buildings, Energy Conversion and Management, and Science and Technology for the Built Environment. In addition, the following standards and guidelines were reviewed for comparison: REHVA, EN, ISO, and ASHRAE.

3 Results

\subsection{Suggested Heat Transfer Coefficients}

\subsubsection{Standards and Guidelines}

Table 1 lists the total and convective heat transfer coefficients used in standards and guidelines.

Either a fixed value or a temperature-dependent expression is presented for each type of surface.

For the total heat transfer coefficients, similar values are given in each standard. Similarly, although 
1 the reference temperature is not specified, REHVA [4], EN [5, 6], and ISO [7] all share the

2 assumption that radiant heat transfer coefficients may be set to $5.5 \mathrm{~W} /\left(\mathrm{m}^{2} \cdot \mathrm{K}\right)$ in a temperature range

3 between $15^{\circ} \mathrm{C}$ and $35^{\circ} \mathrm{C}$.

5 On the other hand, ASHRAE [8] does not provide total or radiant heat transfer coefficients but

6 suggests that radiant heat flux should be calculated based on the MRT method. In most cases,

7 surface emissivity within a room is assumed to be about 0.9 , resulting in a calculation between the

8 fourth power of the cooled/heated surface temperature and the area-weighted Average

9 Unheated/uncooled Surface Temperature (AUST). In addition, ASHRAE provides expressions for

10 the calculation of convective heat flux. The expressions were modified to take the form of a heat

11 transfer coefficient, as shown in Table 1. Two types of expressions are provided, one which takes

12 temperature difference as a single parameter, and the other one which also requires the hydraulic

13 diameter or the height of the cooled/heated surface. Making the assumption that the effect of room

14 dimensions has little effect on the results in most cases, ASHRAE suggests that the simple,

15 single-parameter expressions be used, except for very large spaces such as hangars and warehouses. 


\section{ACCEPTED MANUSCRIPT}

Table 1. Heat transfer coefficients provided in standards and guidelines

\begin{tabular}{|c|c|c|c|c|}
\hline Standard/Guideline & Surface Type & $h_{t o t}\left(\mathbf{W} /\left(\mathbf{m}^{2} \cdot \mathbf{K}\right)\right)$ & Reference Temp. & Notes \\
\hline \multirow{5}{*}{ REHVA [4] } & Ceiling Cooling & 11 & \multirow{15}{*}{$T_{o p}$} & \\
\hline & Ceiling Heating & 6 & & \\
\hline & Floor Cooling & 7 & & \\
\hline & Floor Heating & 11 & & \\
\hline & Wall Cooling / Heating & 8 & & \\
\hline \multirow{5}{*}{ EN1264-5 [5] } & Ceiling Cooling & 10.8 & & \\
\hline & Ceiling Heating & 6.5 & & $h_{r}$ assumed to be \\
\hline & Floor Cooling & 6.5 & & $5.5 \mathrm{~W} /\left(\mathrm{m}^{2} \cdot \mathrm{K}\right)$ in \\
\hline & Floor Heating & 10.8 & & temperature range of \\
\hline & Wall Cooling / Heating & 8 & & \\
\hline \multirow{5}{*}{$\begin{array}{l}\text { EN15377-1 [6] } \\
\text { ISO 11855-2 [7] }\end{array}$} & Ceiling Cooling & $8.92 \cdot\left|T_{s}-T_{o p}\right|^{0.1}$ & & \\
\hline & Ceiling Heating & 6 & & \\
\hline & Floor Cooling & 7 & & \\
\hline & Floor Heating & $8.92 \cdot\left|T_{s}-T_{o p}\right|^{0.1}$ & & \\
\hline & Wall Cooling / Heating & 8 & & \\
\hline Standard/Guideline & Surface Type & $h_{c}\left(\mathbf{W} /\left(\mathbf{m}^{2} \cdot \mathbf{K}\right)\right)$ & Reference Temp. & Notes \\
\hline \multirow{7}{*}{ ASHRAE [8] } & Ceiling Cooling & $2.42 \cdot\left|T_{s}-T_{a}\right|^{0.31} / D^{0.08}$ & \multirow{7}{*}{$T_{a}$} & \multirow{4}{*}{$\begin{array}{l}\text { For large spaces where } \\
\text { room size cannot be } \\
\text { ignored }\end{array}$} \\
\hline & Ceiling Heating & $0.20 \cdot\left|T_{s}-T_{a}\right|^{0.25} / D^{0.25}$ & & \\
\hline & Floor Heating & $2.42 \cdot\left|T_{s}-T_{a}\right|^{0.31} / \mathrm{D}^{0.08}$ & & \\
\hline & Wall Cooling / Heating & $1.87 \cdot\left|T_{s}-T_{a}\right|^{0.32} / H^{0.08}$ & & \\
\hline & Ceiling Cooling & $2.13 \cdot\left|T_{s}-T_{a}\right|^{0.31}$ & & \multirow{3}{*}{$\begin{array}{c}\text { Simplified calculation } \\
(D=4.91 \mathrm{~m}, \\
H=2.7 \mathrm{~m})\end{array}$} \\
\hline & Ceiling Heating & $0.134 \cdot\left|T_{s}-T_{a}\right|^{0.25}$ & & \\
\hline & $\begin{array}{c}\text { Floor Heating } \\
\text { Wall Cooling / Heating }\end{array}$ & $\begin{array}{l}2.13 \cdot\left|T_{s}-T_{a}\right|^{0.31} \\
1.78 \cdot\left|T_{s}-T_{a}\right|^{0.32}\end{array}$ & & \\
\hline
\end{tabular}

\subsubsection{Literature}

A total of 19 articles were reviewed, out of which 10, 5, and 5 observed the ceiling, floor, and wall, respectively. Some articles reviewed multiple surfaces. Only articles focusing on the surface heat transfer coefficients of radiant systems were chosen, excluding articles which handled inner surface (uncooled/unheated wall, floor, or ceiling surface) heat transfer in general. Table 2 lists the values found in the literature. Most values were obtained in experiments, with several exceptions that performed a computational analysis [22, 26, 27].

First, the radiant heat transfer coefficients were overall in good agreement with the standards in

Table 1. Similar values of around 5-6 W/( $\left.\mathrm{m}^{2} \cdot \mathrm{K}\right)$ were seen for the radiant heat transfer coefficients, 
1 except for the wall systems, which had a lower value of $4.3 \mathrm{~W} /\left(\mathrm{m}^{2} \cdot \mathrm{K}\right)$. While the majority used

2 AUST as the reference temperature, Karadağ [22] used the air temperature as a reference

3 temperature, and surrounding wall temperature as an adjusting variable in order to simplify the

4 calculation process. It was assumed that the influence of the surrounding surfaces would be

5 included in the air temperature if no other heating/cooling sources were present in the room.

7 The total and convective heat transfer coefficients varied over a wide range, even for the same

8 position and operation mode of the surface. For the total heat transfer coefficient, the reference

9 temperatures were either air or operative temperature, the latter being more common in the cases

10 shown here. However, Yuan et al. [19] pointed out that the same operative temperature may be

11 found in different combinations of air temperature and mean radiant temperature (MRT), and thus

12 included the supply water temperature in the expression to calculate the total heat transfer

13 coefficient. This differentiates the cases with the same operative temperature but with different air

14 temperature and MRT, which on the other hand requires an experimental approach to obtain

15 additional coefficients.

As an effect of buoyancy, the convective heat transfer varies depending on the position of the radiant surface and the temperature difference between it and air. In general, ceiling cooling and floor heating have a higher convective heat transfer coefficient as compared to ceiling heating and 


\section{ACCEPTED MANUSCRIPT}

1 will show similar tendencies as the convective heat transfer (i.e. the total heat flux will increase

2 with increasing convective heat transfer coefficient, and vice versa). Since the convective heat

3 transfer is strongly affected by the contact area between the surface and the surrounding air, it may

4 be enhanced by applying fins, as was the case in Zhang et al. [12]. In this case, however, the

5 convective and total heat flux for the ceiling heating examples were larger than those of the ceiling

6 cooling cases, which the authors describe as being the result of the large room dimension and the

7 position of the panels. Another case that stands out is the ceiling heating and floor cooling

8 measurements reported by Cholewa et al. [15, 16], which indicated a convective heat transfer

9 coefficient of 0.0 and $0.1 \mathrm{~W} /\left(\mathrm{m}^{2} \cdot \mathrm{K}\right)$, respectively. A different approach to the calculation of

10 convective heat transfer was taken in these cases, and is discussed in the following section. 
Table 2. Heat transfer coefficients in the literature

\begin{tabular}{|c|c|c|c|c|c|c|c|c|}
\hline \multirow{2}{*}{ Author } & \multirow{2}{*}{$\begin{array}{c}\text { Surface } \\
\text { Type }^{\text {a) }}\end{array}$} & \multicolumn{3}{|c|}{ Heat Transfer Coefficient $\left(W /\left(\mathbf{m}^{2} \cdot \mathbf{K}\right)\right)$} & \multicolumn{3}{|c|}{ Reference Temperature } & \multirow{2}{*}{ Conditions } \\
\hline & & Total & Radiant & Convective & Total & Radiant & Convective & \\
\hline \multirow{4}{*}{ Okamoto et al. [9] } & \multirow{2}{*}{$\mathrm{CH}$} & & 5.65 & 1.69 & \multirow{4}{*}{-} & & \multirow{4}{*}{$\mathrm{n} / \mathrm{a}$} & meandering pipe layout \\
\hline & & - & 6.05 & 2.54 & & & & spiral pipe layout \\
\hline & \multirow{2}{*}{$\mathrm{CC}$} & - & 5.65 & 2.54 & & & & meandering pipe layout \\
\hline & & & 6.05 & 1.69 & & & & spiral pipe layout \\
\hline Yuan et al. [10] & $\mathrm{CC}$ & $7.6-9.8$ & - & - & $T_{a}$ & - & - & - \\
\hline Acikgoz and Kincay [11] & $\mathrm{WC}$ & 8.1 & 4.3 & 2.7 & $T_{a}$ & AUST & $T_{a}$ & - \\
\hline \multirow{4}{*}{ Zhang et al. [12] } & $\mathrm{CC}^{*}$ & 8.4 & 5.3 & 3.2 & \multirow{4}{*}{$T_{o p}$} & \multirow{4}{*}{ AUST } & \multirow{4}{*}{$T_{a}$} & panels with fins \\
\hline & $\mathrm{CH}^{*}$ & 6.8 & 5.7 & 1.1 & & & & *typical office room \\
\hline & $\mathrm{CC}^{* *}$ & 9.2 & 5.8 & 4.0 & & & & **high ceiling, glass curtain \\
\hline & $\mathrm{CH}^{* *}$ & 11.8 & 5.7 & 5.9 & & & & wall \& ceiling \\
\hline Andrés-Chicote et al. [13] & $\mathrm{CC}$ & 8.5 & 5.4 & $4.2 \bigcirc$ & $T_{o p}$ & AUST & $T_{a}$ & - \\
\hline \multirow{2}{*}{ Causone et al. [14] } & $\mathrm{CC}$ & 13.2 & 5.6 & $4.4 \square$ & \multirow{2}{*}{$T_{o p}$} & \multirow{2}{*}{ AUST } & \multirow{2}{*}{$T_{a}$} & \multirow{2}{*}{-} \\
\hline & $\mathrm{CH}$ & 5.8 & 5.6 & 0.3 & & & & \\
\hline \multirow{2}{*}{ Cholewa et al. [15] ${ }^{\text {b) }}$} & $\mathrm{CH}$ & 5.6 & 5.5 & 0.0 & \multirow{2}{*}{$T_{o p}$} & \multirow{2}{*}{ AUST } & \multirow{2}{*}{$T_{a}$} & \multirow{2}{*}{-} \\
\hline & $\mathrm{CC}$ & 9.36. $\left(T_{o p l .1}-T_{s}\right)^{0.1}$ & 5.2 & 2.04-3.65 & & & & \\
\hline \multirow{2}{*}{ Cholewa et al. [16] ${ }^{\text {b) }}$} & $\mathrm{FH}$ & $7.67 \cdot\left(T_{s}-T_{o p l .1}\right)^{0.1}$ & 5.6 & $2.2-3.5$ & \multirow{2}{*}{$T_{o p}$} & \multirow{2}{*}{ AUST } & & \\
\hline & $\mathrm{FC}$ & 5.7 & 5.0 & 0.1 & & & $T_{a}$ & - \\
\hline & WH & 8.57 & 5.74 & 2.44 & & & & \\
\hline Koca and Çetın [17] & $\mathrm{CH}$ & 7.28 & 5.7 & 0.82 & $T_{o p}$ & AUST & $T_{a}$ & - \\
\hline & & $8.46-8.94$ & $5.38-5.57$ & $3.07-3.22$ & & & & one wall $\left(4.4 \mathrm{~m}^{2}\right)$ \\
\hline Koca et al. [18] & WH & $8.16-8.48$ & $5.38-5.57$ & $2.25-2.40$ & $T_{o p}$ & AUST & $T_{a}$ & one wall $\left(11 \mathrm{~m}^{2}\right)$ \\
\hline & & $8.76-9.28$ & $5.98-6.25$ & $2.59-2.73$ & & & & two walls $\left(11+4.4=15.4 \mathrm{~m}^{2}\right)$ \\
\hline Yuan et al [19] & $\mathrm{CC}$ & $7.49 \cdot\left|T_{s}-T_{w, s u p}\right|^{-0.032} \cdot \mid T_{o p}-$ & Y. & - & & - & - & 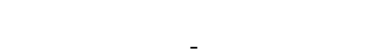 \\
\hline Yuan et al. [19] & $\mathrm{CH}$ & $6.684 \cdot\left|T_{s}-T_{w, s u p}\right|^{-0.139} \cdot \mid T_{o p}$ & - & - & $I_{o p}$ & - & - & - \\
\hline & $\mathrm{CC}$ & & & 3.0 & & & & panel front-side \\
\hline Miriel et al. [20] & $c$ & - & - & 0.8 & - & - & $T_{a}$ & panel backside \\
\hline & $\mathrm{CH}$ & - & - & 1.25 & - & - & (room/plenum) & panel front-side \\
\hline & $\mathrm{CH}$ & & & 1.75 & & & & panel backside \\
\hline & WH & & & $\left(1.823 / D^{0.121}\right)\left(T_{s}-T_{a}\right)^{0.293}$ & & & & \\
\hline Awbi and Hatton [21] & $\mathrm{FH}$ & - & - & $\left(2.175 / D^{0.076}\right)\left(T_{s}-T_{a}\right)^{0.308}$ & - & - & $T_{a}$ & - \\
\hline & $\mathrm{CH}$ & & & $\left(0.704 / D^{0.601}\right)\left(T_{s}-T_{a}\right)^{0.133}$ & & & & \\
\hline Karadağ [22] & $\mathrm{CC}$ & $11.5 \cdot \varepsilon \cdot\left(T_{a}-T_{s}\right)^{0.09}$ & - & $3.1 \cdot\left(T_{a}-T_{s}\right)^{0.22}$ & $T_{a}$ & - & $T_{a}$ & - \\
\hline Olesen et al. [23] & $\mathrm{FC}$ & 7.5 & 5.5 & 1.0 & $T_{o p}$ & AUST & $T_{a}$ & - \\
\hline
\end{tabular}




\begin{tabular}{|c|c|c|c|c|c|c|c|c|}
\hline \multirow{2}{*}{ Author } & \multirow{2}{*}{$\begin{array}{c}\text { Surface } \\
\text { Type a) }\end{array}$} & \multicolumn{3}{|c|}{ Heat Transfer Coefficient $\left(\mathbf{W} /\left(\mathbf{m}^{2} \cdot \mathbf{K}\right)\right)$} & \multicolumn{3}{|c|}{ Reference Temperature } & \multirow{2}{*}{ Conditions } \\
\hline & & Total & Radiant & Convective & Total & Radiant & Convective & \\
\hline Evren et al. [24] & $\mathrm{FH}$ & $9.9^{*}, 10.1 * *$ & 5.4 & 3.7 & $T_{o p}$ & AUST & $T_{a}$ & $\begin{array}{l}\text { Based on: } \\
* \text { calculated } q_{t o t} \\
* * \text { measured } q_{t o t}\end{array}$ \\
\hline Khalifa [3] & $\begin{array}{l}\mathrm{FH} \\
\mathrm{CH} \\
\end{array}$ & - & - & $\begin{array}{c}2.416\left(T_{s}-T_{a}\right)^{0.31} / D^{0.076} \\
0.203\left(T_{s}-T_{a}\right)^{0.25} / D^{0.24} \\
\end{array}$ & - & & $T_{a}$ & Quoted from Min et al. [25] \\
\hline Karadağ [26] & $\mathrm{CC}$ & - & $8 \cdot \varepsilon \cdot\left(T_{a}-T_{s}\right)^{m}$ & $2.6 \cdot\left(T_{a}-T_{s}\right)^{0.27}$ & - & $T_{a}$ & $T_{a}$ & $\begin{array}{l}-0.06<\mathrm{m}<-0.1 \\
\text { (wall temp. dependent) }\end{array}$ \\
\hline Acikgoz [27] & WH & $\begin{array}{c}10 \varepsilon^{0.80}\left(T_{s}-T_{a}\right)^{0.07} \\
10.50\end{array}$ & $\begin{array}{c}- \\
5.50\end{array}$ & $\begin{array}{c}1.5(H / L)^{0.09}\left(T_{s}-T_{a}\right)^{0.47} \\
3.50\end{array}$ & $T_{a}$ & $\begin{array}{c}- \\
A U S T\end{array}$ & $T_{a}$ & - \\
\hline
\end{tabular}

${ }^{\text {a) }} \mathrm{CC}$ : ceiling cooling, CH: ceiling heating, FC: floor cooling, FH: floor heating, WC: wall cooling, WH: wall heating

${ }^{b)}$ the subscript 1.1 indicates the height of measurement (m) 


\subsection{Measurement Data Comparison}

\section{ACCEPTED MANUSCRIPT}

\subsubsection{Ceiling Cooling}

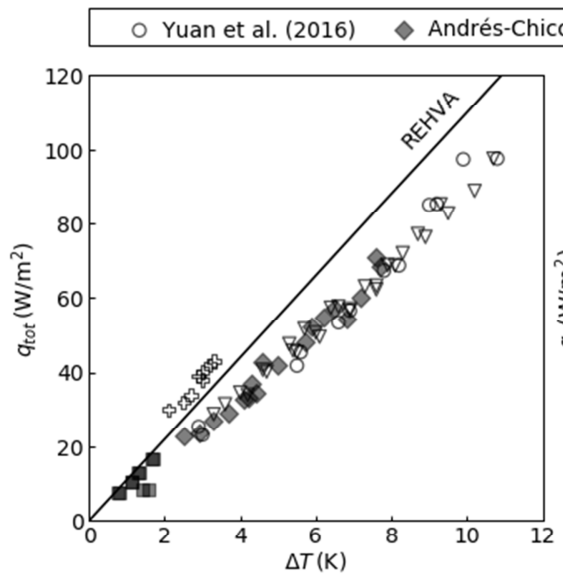

(a) Total Heat Flux

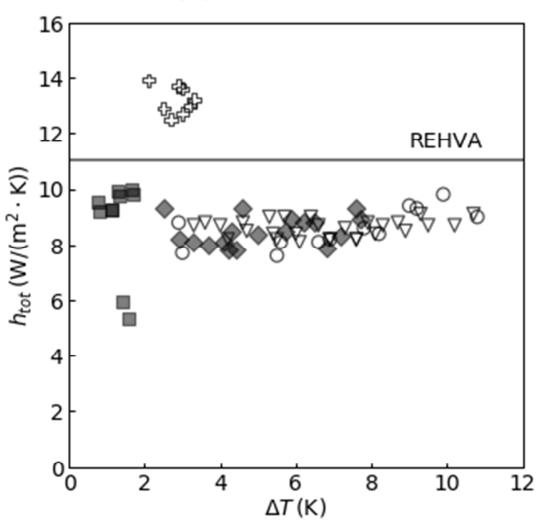

(d) Total Heat Transfer Coefficient

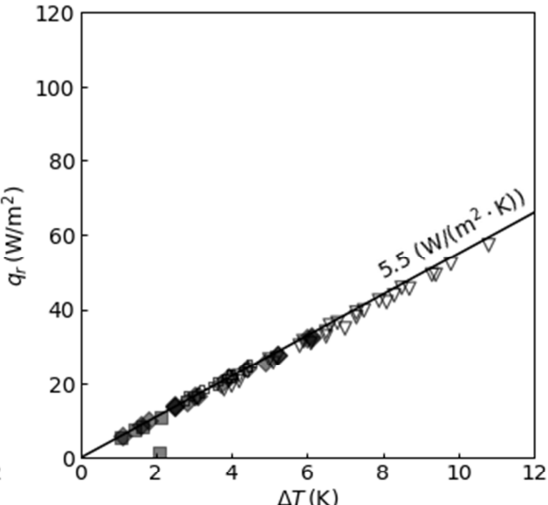

(b) Radiant Heat Flux

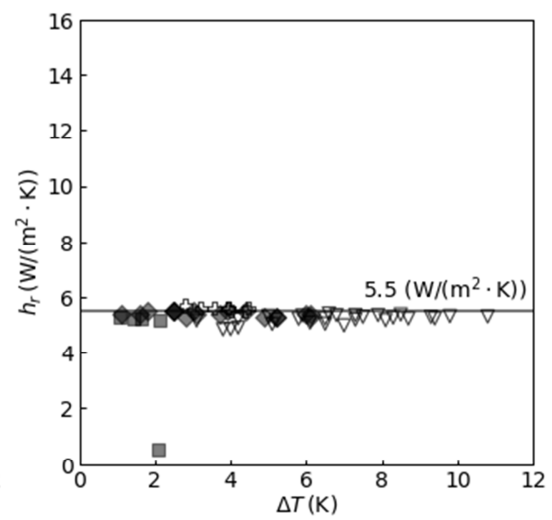

(e) Radiant Heat Transfer Coefficient

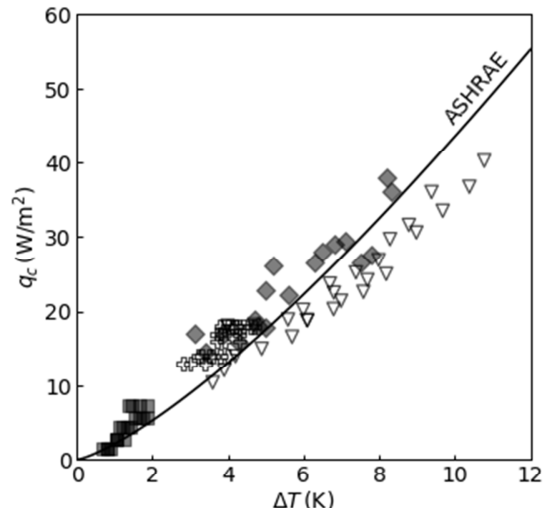

(c) Convective Heat Flux

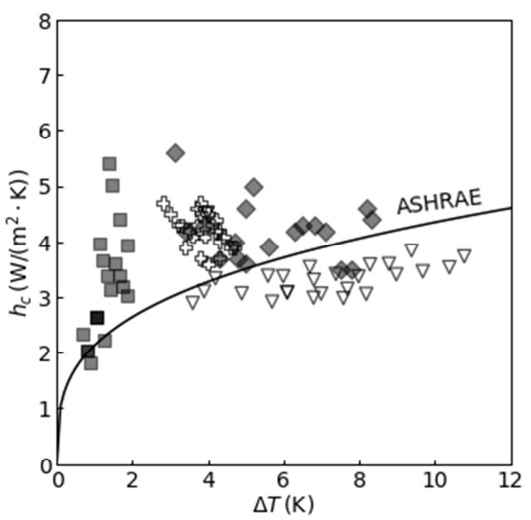

(f) Convective Heat Transfer Coefficient

Fig. 1 Measured heat flux and heat transfer coefficients (ceiling cooling)

Fig. 1 shows the measured heat flux and heat transfer coefficients for ceiling cooling measurements in the literature. The $\Delta T$ represents the temperature difference between the cooled surface and the reference temperature specified in each article. For comparison purposes, the heat transfer coefficients proposed by REHVA [4] and ASHRAE [8] (simplified calculation) and the heat flux calculated from them are illustrated. As previously mentioned, many standards and guidelines shared the assumption of $5.5 \mathrm{~W} /\left(\mathrm{m}^{2} \cdot \mathrm{K}\right)$ for the radiant heat transfer coefficient, so this was also included in Fig. 1.

Results show that the radiant heat flux had a highly linear correlation with $\Delta T$, resulting in a consistent radiant heat transfer coefficient of about $5.5 \mathrm{~W} /\left(\mathrm{m}^{2} \cdot \mathrm{K}\right)$ throughout the literature. The 
outlying data points were from cases with aluminum foil on the cooled surface, with a lower emissivity (0.1) [15]. These same deviations can naturally be seen in the total heat transfer coefficient. Overall, the total heat transfer coefficients were between $8-10 \mathrm{~W} /\left(\mathrm{m}^{2} \cdot \mathrm{K}\right)$, lower than the value suggested by REHVA $\left(11 \mathrm{~W} /\left(\mathrm{m}^{2} \cdot \mathrm{K}\right)\right)$ [4], except for the cases reported by Causone et al. [14], which had a value between $12-14 \mathrm{~W} /\left(\mathrm{m}^{2} \cdot \mathrm{K}\right)$. The convective heat transfer coefficients, on the other hand, differed to a much greater extent within and between articles, ranging from $2-6 \mathrm{~W} /\left(\mathrm{m}^{2} \cdot \mathrm{K}\right)$. The results reported by Cholewa et al. [15] deviated the most, due to the use of multiple reference temperatures for the same measurements. Calculation within a small band of $\Delta T$ may have had an

9 effect as well. The values obtained by Yuan et al. [19] remained at 3-4 W/( $\left.\mathrm{m}^{2} \cdot \mathrm{K}\right)$ within a large band of $\Delta T$ (between 3-12 K). Larger variation of the convective heat transfer coefficient occurred 1 between articles and in comparison with the suggested value when the $\Delta T$ was below $5 \mathrm{~K}$. 


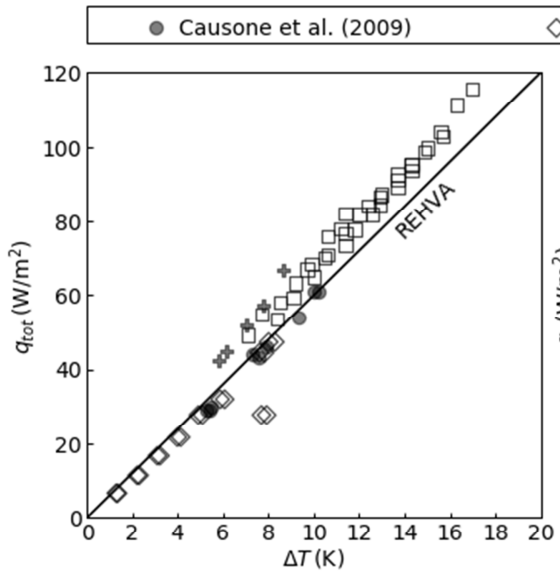

(a) Total Heat Flux

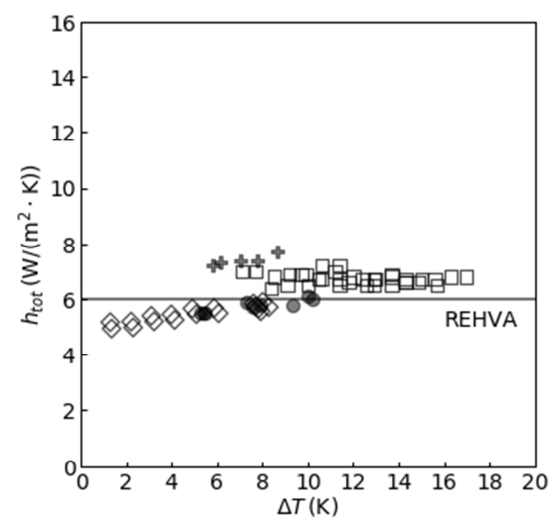

(d) Total Heat Transfer Coefficient $\checkmark$ Cholewa et al. (2017) $\quad+$ Koca and Cetin (2017)

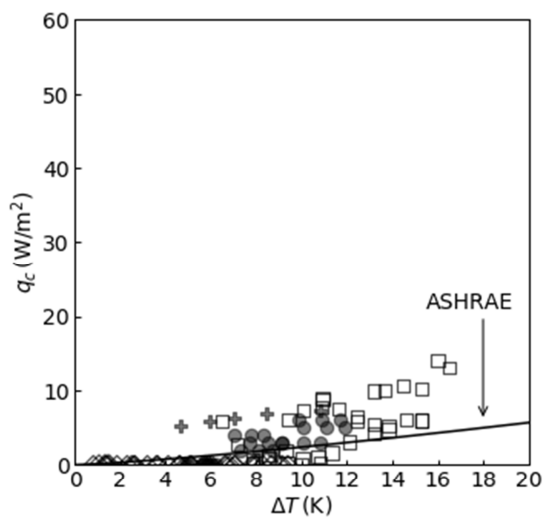

(c) Convective Heat Flux

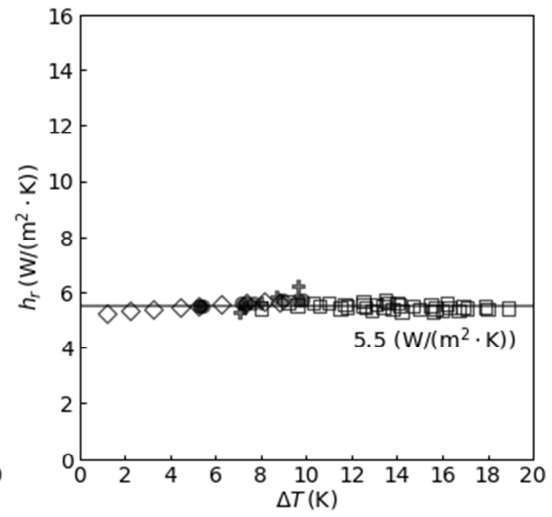

(e) Radiant Heat Transfer Coefficient

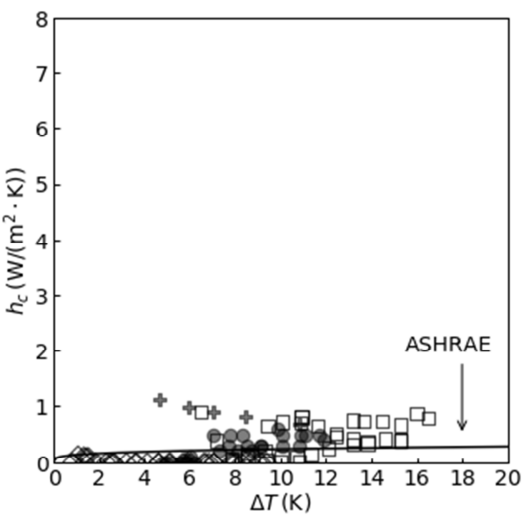

(f) Convective Heat Transfer Coefficient

Fig. 2 Measured heat flux and heat transfer coefficients (ceiling heating)

Fig. 2 shows the measured heat flux and heat transfer coefficients for ceiling heating measurements in the literature. Since the heated surface is not in direct contact with the occupants, a higher surface temperature to compensate for the low convective heat transfer can be used, resulting in a wider range of $\Delta T$ (however, increasing the ceiling surface temperature too much will result in local thermal discomfort, as people are more sensitive to radiant temperature asymmetry caused by warm ceilings [28]). As for ceiling cooling, the radiant heat flux showed a linear correlation with $\Delta T$, resulting in a constant radiant heat transfer coefficient. The total heat transfer coefficients generally ranged between $6-8 \mathrm{~W} /\left(\mathrm{m}^{2} \cdot \mathrm{K}\right)$, while some cases with a $\Delta T$ lower than $8 \mathrm{~K}$ had a lower value and a slight temperature dependency $[14,15]$. Unlike the case of ceiling cooling, ceiling heating caused very little convective heat transfer, so most of the heat transfer took place by radiation. The resulting convective heat transfer coefficients were within $0-1 \mathrm{~W} /\left(\mathrm{m}^{2} \cdot \mathrm{K}\right)$. 


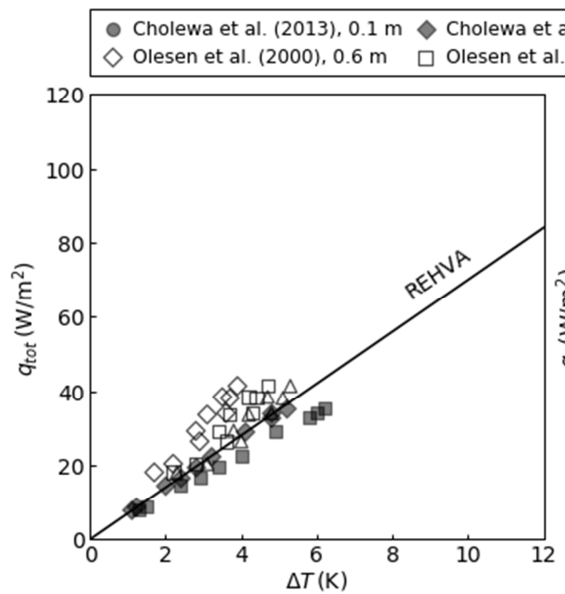

(a) Total Heat Flux

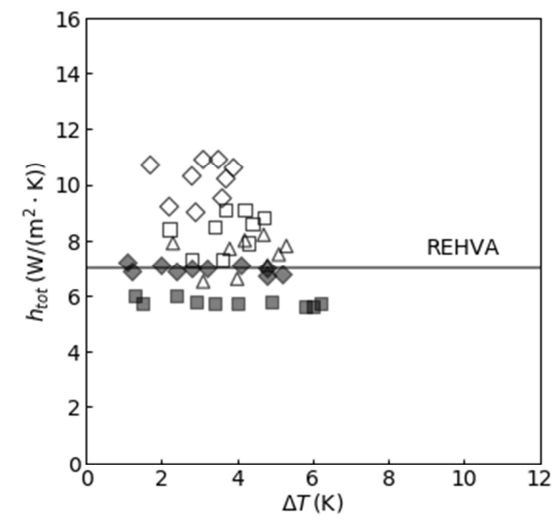

(d) Total Heat Transfer Coefficient

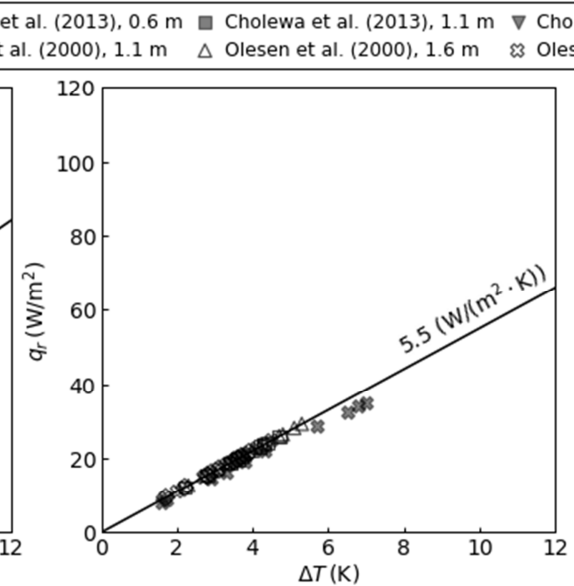

(b) Radiant Heat Flux

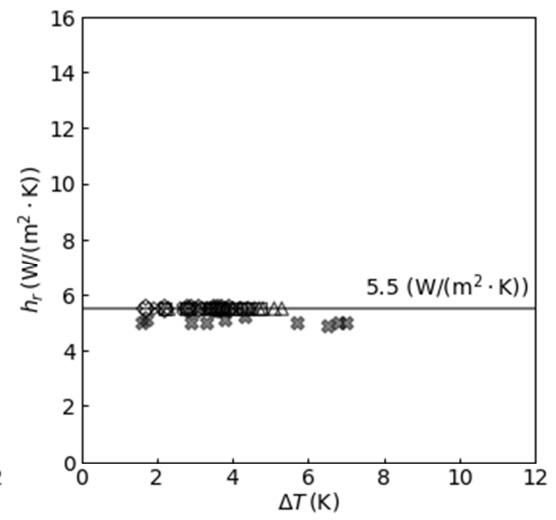

(e) Radiant Heat Transfer Coefficient

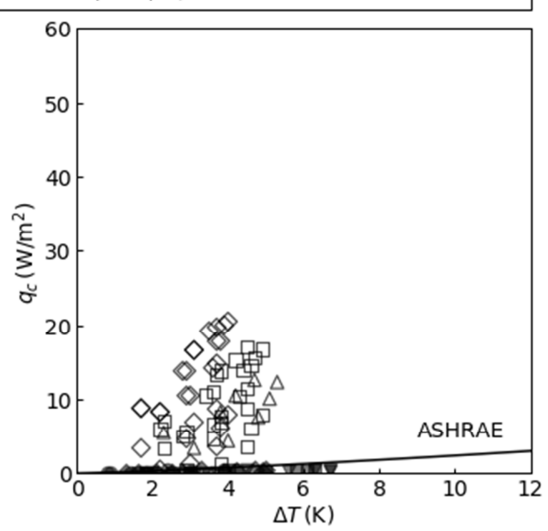

(c) Convective Heat Flux

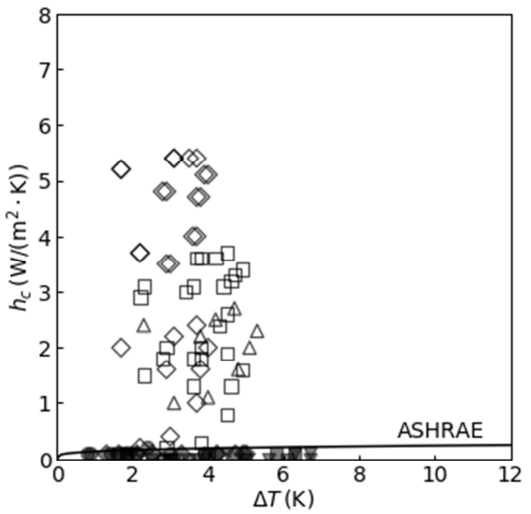

(f) Convective Heat Transfer Coefficient

Number after the year indicates reference temperature measurement height

Fig. 3 Measured heat flux and heat transfer coefficients (floor cooling)

Fig. 3 shows the measurement results for floor cooling. Unlike what was seen above for ceiling cooling and heating, the total heat flux plots do not suggest a single linear correlation. The measured values were plotted separately according to the measurement height of the reference temperature, and this is indicated by the numbers after the author and year in the legend. Even though the resulting total heat transfer coefficient of the two identified studies had a large range of values between $6-11 \mathrm{~W} /\left(\mathrm{m}^{2} \cdot \mathrm{K}\right)$, the values in the same article that were obtained at the same measurement height tended to cluster around a nearly constant value. In general, the resulting heat transfer coefficient became larger as the measurement height was located closer to the floor (i.e. to the cooled surface). 
2 value of $5.5 \mathrm{~W} /\left(\mathrm{m}^{2} \cdot \mathrm{K}\right)$, and the radiant heat flux was calculated using different reference

In the article by Olesen et al. [23], the radiant heat transfer coefficient was assumed to be a constant temperatures. The operative temperature and MRT were used for the measurement height of 0.6 and $1.1 \mathrm{~m}$, the globe temperature for $1.6 \mathrm{~m}$, and the AUST for the "n/a" indicated in the legend. Regardless of the choice of reference temperature, the radiant heat flux resulted in similar values within the article and were similar to those reported by Cholewa et al. [16]. The radiant heat transfer coefficients obtained in these two studies were also similar.

The difference between the two articles is apparent in the convective heat flux, and thus also in the total heat flux. Measurement results reported by Cholewa et al. [16] indicated that the convective heat flux and heat transfer coefficient were nearly zero in all cases. The results reported by Olesen et al. [23] were in the range $0-6 \mathrm{~W} /\left(\mathrm{m}^{2} \cdot \mathrm{K}\right)$, depending on the measurement height. 


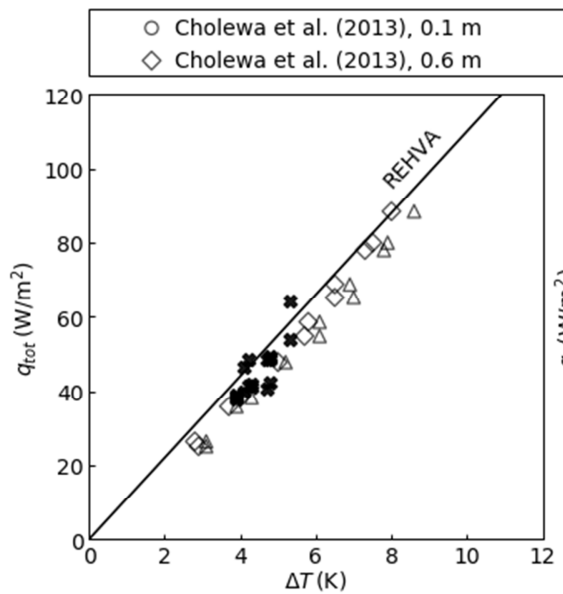

(a) Total Heat Flux

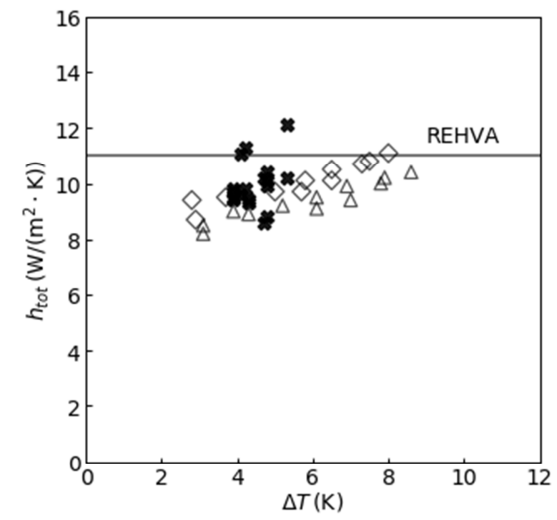

(d) Total Heat Transfer Coefficient

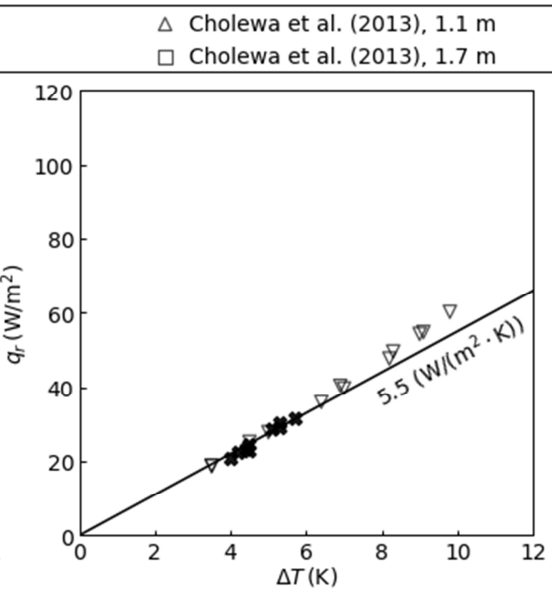

(b) Radiant Heat Flux

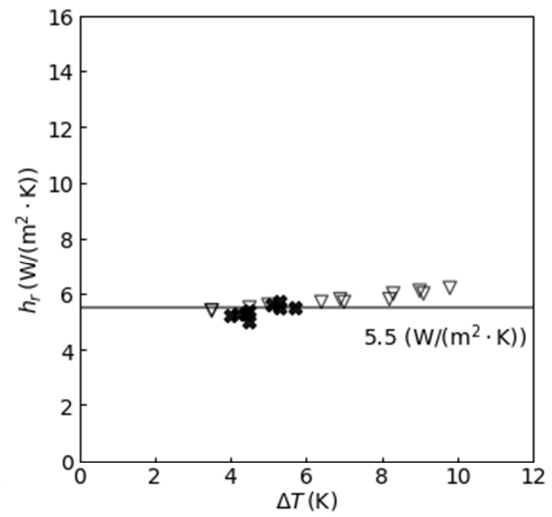

(e) Radiant Heat Transfer Coefficient $\nabla$ Cholewa et al. (2013), n/a

* Evren et al. (2017), n/a

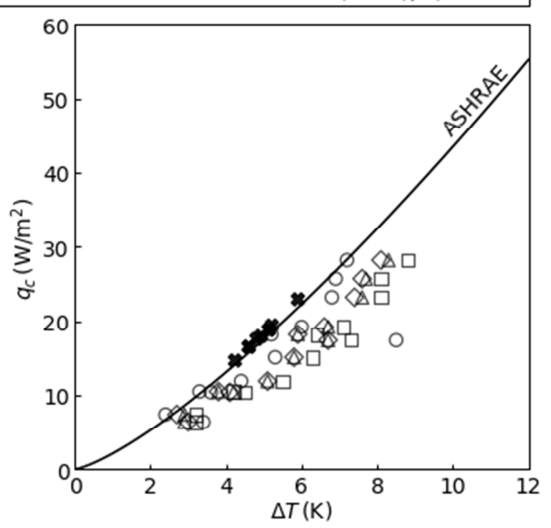

(c) Convective Heat Flux

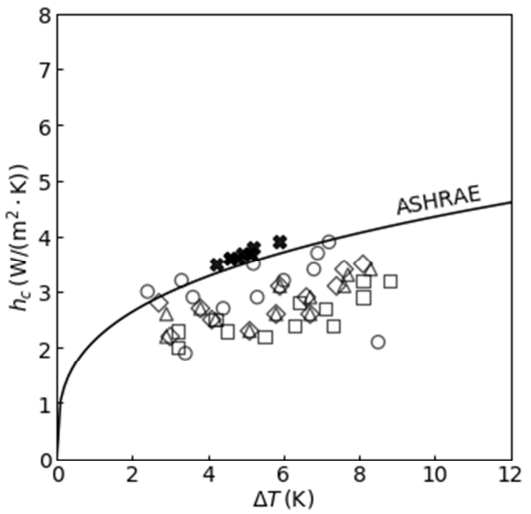

(f) Convective Heat Transfer Coefficient

Number after the year indicates reference temperature measurement height

Fig 4. Measured heat flux and heat transfer coefficients (floor heating)

Measurement results for floor heating are shown in Fig. 4. As with floor cooling, the results were plotted separately according to the reference temperature measurement height. Although the radiant heat transfer coefficients resulted in a small deviation from the other values, as with all the other cases, a slight temperature dependency was seen in one study [16]. The total heat transfer coefficient took a higher value as $\Delta T$ increased, ranging between $8-12 \mathrm{~W} /\left(\mathrm{m}^{2} \cdot \mathrm{K}\right)$. However, as for floor cooling, there was an effect of measurement height: a higher heat transfer coefficient was seen when temperature was measured closer to the heated surface. The convective portion displayed a similar tendency as the total heat flux, with the heat transfer coefficients ranging between 2-4 $\mathrm{W} /\left(\mathrm{m}^{2} \cdot \mathrm{K}\right)$ 


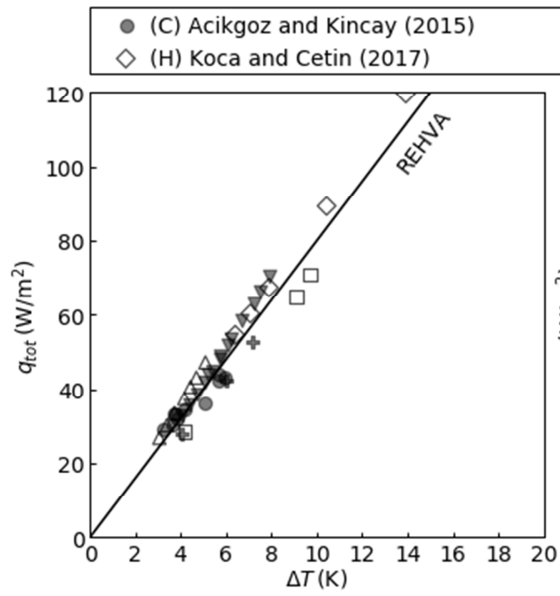

(a) Total Heat Flux

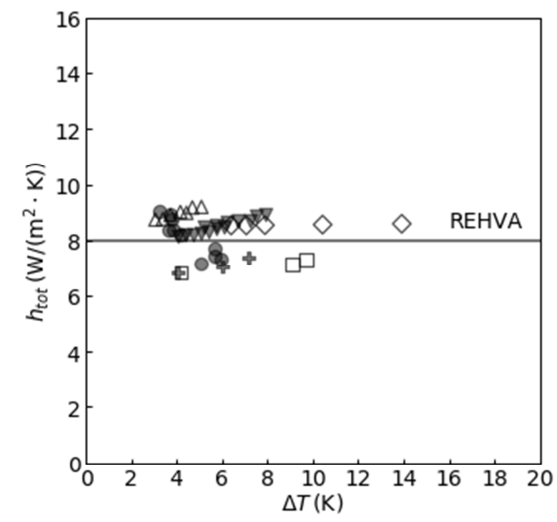

(d) Total Heat Transfer Coefficient
$+(\mathrm{H})$ Koca and Cetin (2017) wall+ceiling (wall)* $\square(\mathrm{H})$ Koca and Cetin (2017) wall+ceiling (ceiling)*

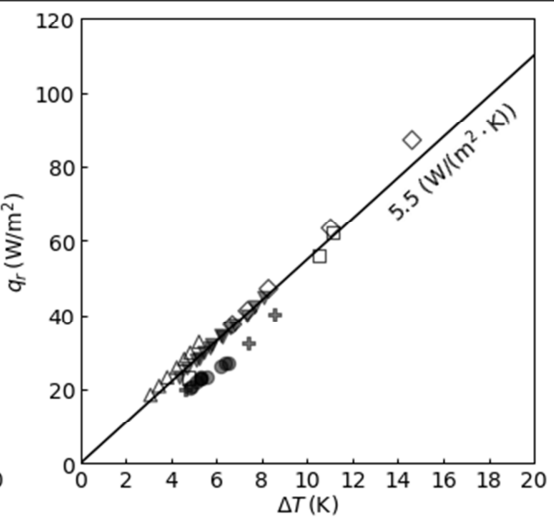

(b) Radiant Heat Flux

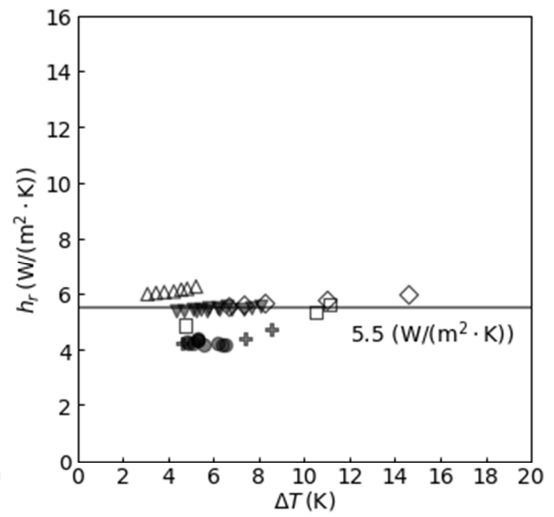

(e) Radiant Heat Transfer Coefficient

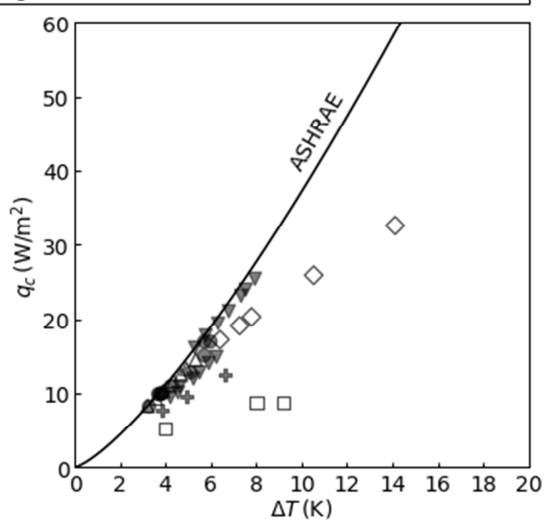

(c) Convective Heat Flux

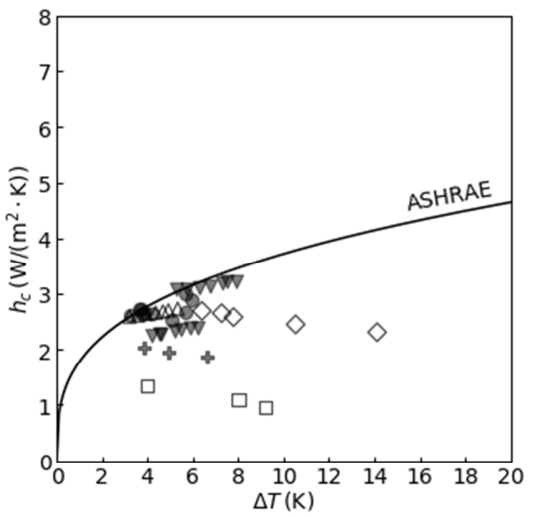

(f) Convective Heat Transfer Coefficient

(C): cooling cases, $(\mathrm{H})$ : heating cases

*wall+ceiling (wall): measurement of the wall in cases where both the wall and the ceiling are heated, vice versa for wall+ceiling (ceiling)

Fig. 5. Measured heat flux and heat transfer coefficients (wall cooling/heating)

Standards and guidelines recommend using the same the heat transfer coefficient for wall cooling and heating. Fig. 5 shows measurement results for both cases. The values reported by Acikgoz and Kincay [11] were for cooling but all the others were for heating. Only one wall was used as the cooled/heated surface unless otherwise indicated. In addition, when multiple surfaces were used, the observed surface is shown in parenthesis.

Compared to other surfaces, the total heat flux and heat transfer coefficients are closer to the values recommended in REHVA [4] (which is equal to the ones in EN and ISO [5, 6, 7]), but tended to be higher. On the other hand, compared to other surfaces, more outliers are seen in the radiant heat flux. 
It is likely that the size of the wall in comparison with the room and its angle factor with the other surfaces affected the results. For the convective heat flux, measurements observing the ceiling when both wall and ceiling were heated had the lowest value, but were slightly higher than the cases with ceiling heating only (Fig. 2). Measurements by Acikgoz and Kincay [11] and Koca et al. [18] resulted in a convective heat flux very close to the value calculated by the expression given in ASHRAE [8]. However, measurements by Koca and Çetin [17] displayed a smaller increase in heat flux as temperature difference increased, resulting in a large deviation from the suggested values. One possible cause of this discrepancy may be their use of mechanical air conditioners to adjust the thermal conditions in the chamber.

\subsection{Prediction Accuracy}

The purpose of heat transfer coefficients is to predict the amount of heat transfer in a given condition. However, as stated in the previous section, the suggested values and expressions differ for each standard, guideline, and study. Each suggested heat transfer coefficient was therefore used to predict the heat flux to compare with the measurement data plotted in Figs. 1-5 (excluding the $\varepsilon=$ 0.1 cases). In each study, recommended heat transfer coefficients were obtained by correlating multiple measurements of heat flux and temperature difference. A single list combining all the measurements and temperature differences was first compiled. The list consisted of a total of 469 entries, and the number of entries for each surface type was as follows: 115 ceiling cooling, 121 ceiling heating, 113 floor cooling, 78 floor heating, 42 wall cooling/heating. Even when the same measurement data were used, it was considered a different entry when a different reference temperature (temperature difference) was used. Each of the heat transfer coefficients listed in Tables 1 and 2 were then used to predict the heat flux for all the entries with the same surface type. Figs. 6-10 show the distribution of differences between the predicted and measured heat flux for each entry, expressed as percentages. The whiskers represent the furthest data within 1.5 interquartile ranges from the first and third quartiles, and any data out of range are plotted as circles. An error of 
$0 \%$ represents a complete match of the predicted and measured heat flux, and positive and negative errors represent overprediction and underprediction, respectively.
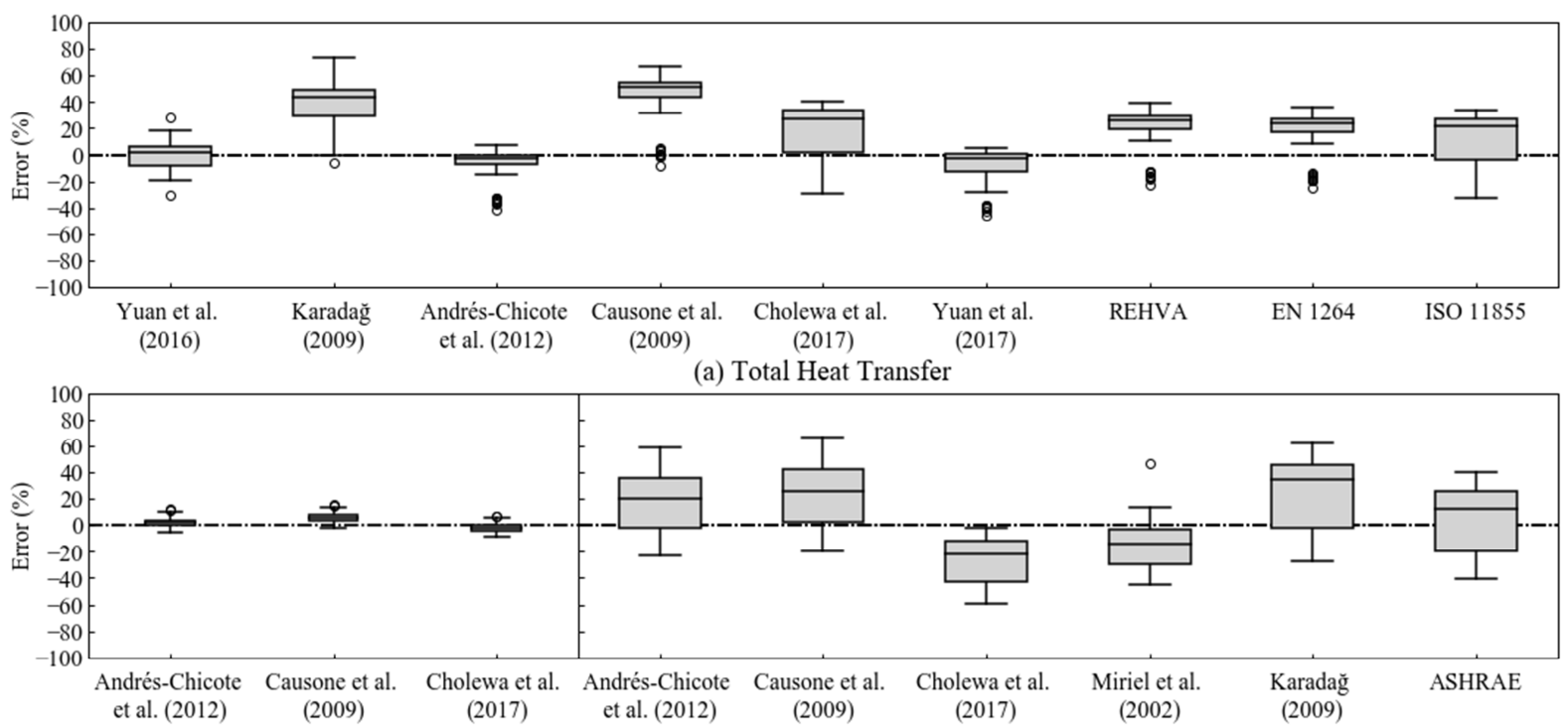

(b) Radiant Heat Transfer

(c) Convective Heat Transfer

Fig. 6 Error between measured and predicted heat flux using the heat transfer coefficients recommended in the literature (ceiling cooling, $\mathrm{n}=115$ )

For the ceiling cooling cases, the radiant heat flux had the highest accuracy for all the suggested values; in all cases, the prediction error was within $\pm 20 \%$. Larger distributions of error were seen in the total and convective heat flux. Regardless of the use of constant values or temperature (and other parameter) dependent expressions, each resulted in a large deviation of $60-80 \%$ in its prediction. Furthermore, most suggested values were on the positive side of the error, meaning that the value was overestimated. For the total heat transfer coefficient, the values proposed by Andrés-Chicote et al. [13] and Yuan et al. [19] resulted in predicted values equal to or less than the measured values. For the convective heat flux, the equation proposed by Cholewa et al. [15] had all the errors on the negative side, which explains their conclusion that most convective heat transfer coefficients in the literature are overestimated. 


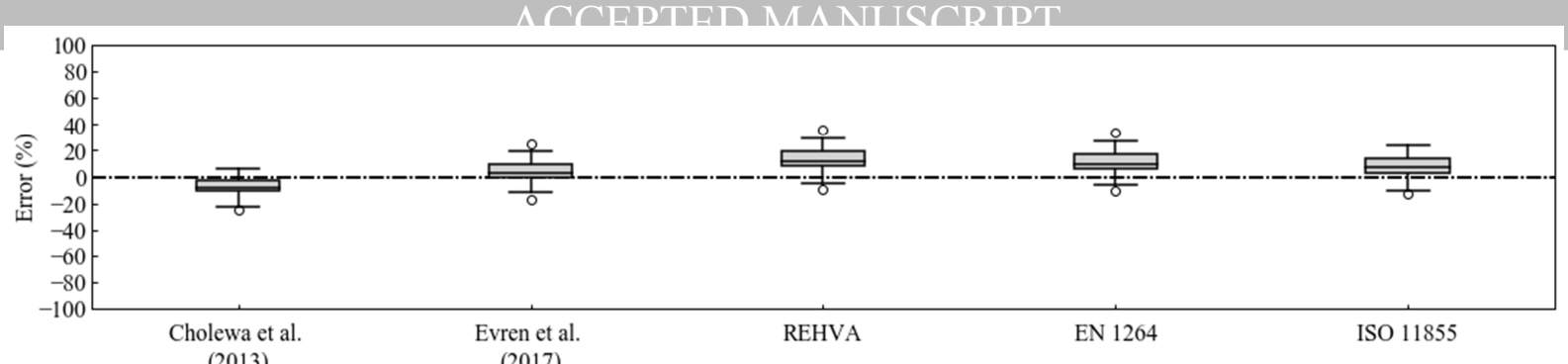

(a) Total Heat Transfer

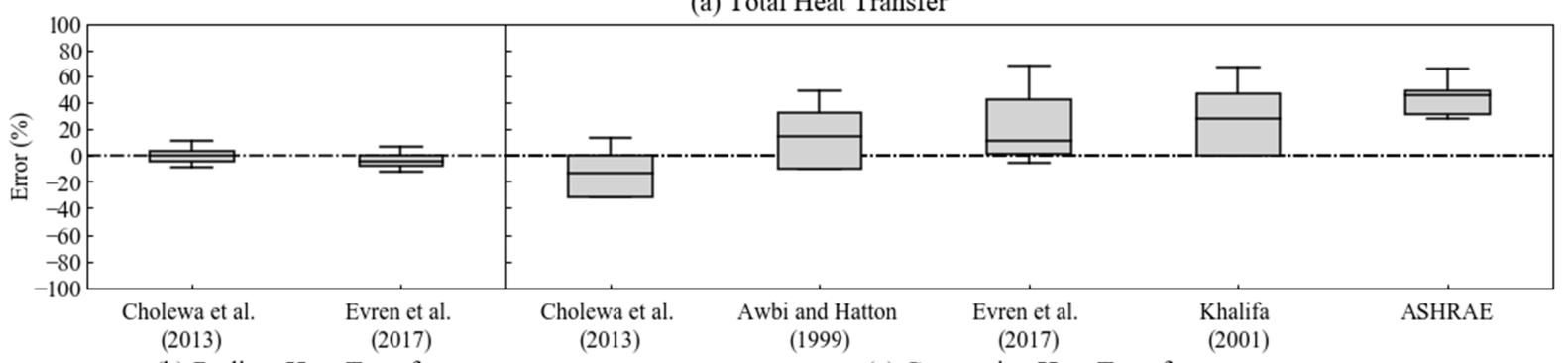

$\begin{array}{ll}\text { (b) Radiant Heat Transfer } & \text { (c) Convective Heat Transfer }\end{array}$

Fig. 7 Error between measured and predicted heat flux using the heat transfer coefficients recommended in the literature (floor heating, $\mathrm{n}=78$ )

5 Similar trends were seen for the radiant and convective heat flux for floor heating. Minimal errors

6 were seen in the radiant heat flux, and most values for the convective heat flux were overpredicted.

7 The total heat flux had a smaller band of distribution and lower percentages of error as compared

8 with the ceiling cooling cases. However, fewer measurements were available for floor heating than

9 for ceiling cooling. 

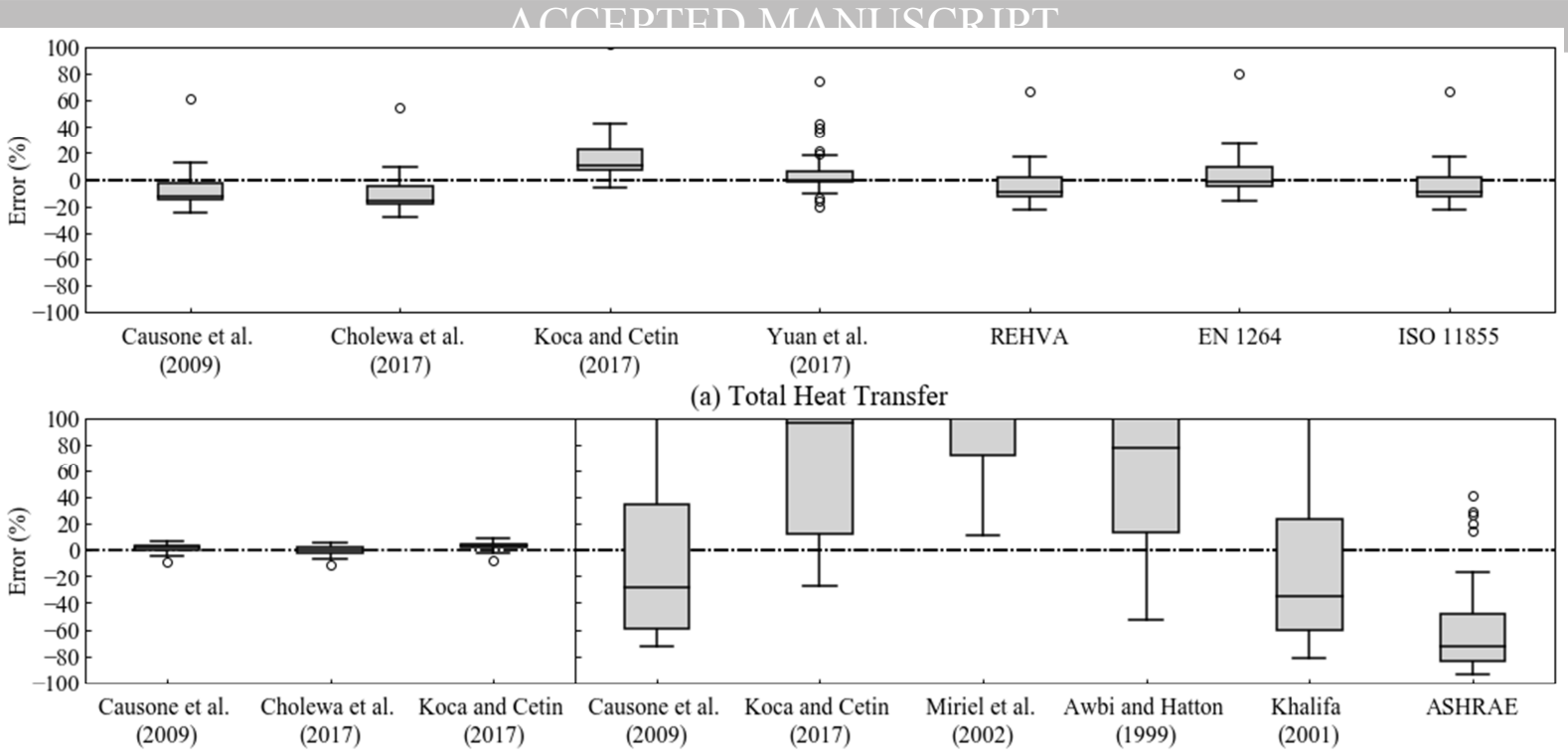

(b) Radiant Heat Transfer

(c) Convective Heat Transfer

Fig. 8 Error between measured and predicted heat flux using the heat transfer coefficients recommended in the literature (ceiling heating, $\mathrm{n}=121$ )

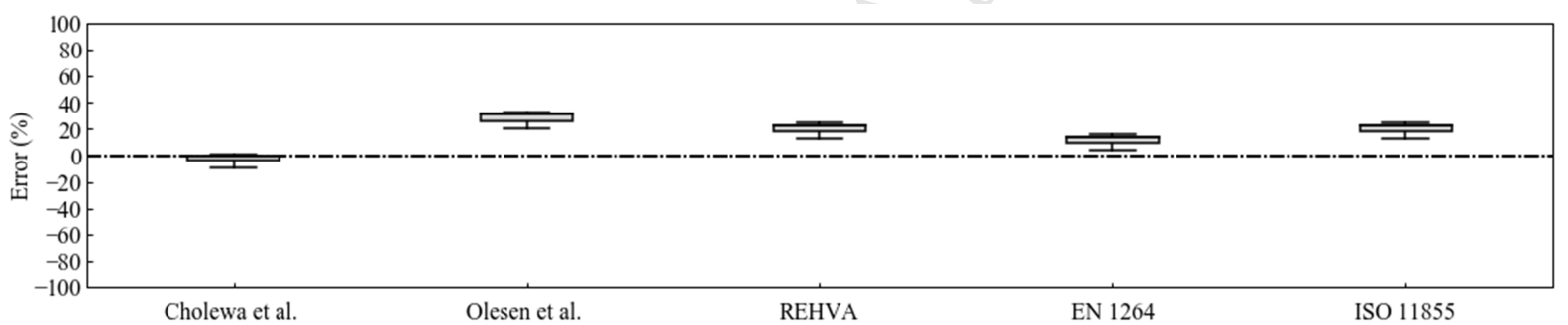

(2013)
(2000)

(a) Total Heat Transfer

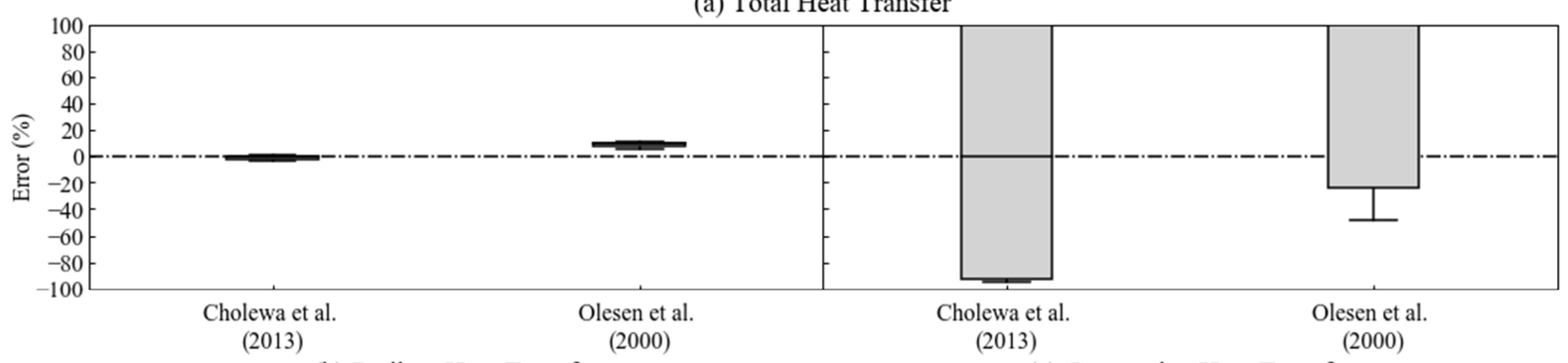

(b) Radiant Heat Transfer

(c) Convective Heat Transfer

Fig. 9 Error between measured and predicted heat flux using the heat transfer coefficients recommended in the literature (floor cooling, $\mathrm{n}=113$ )

For the floor cooling and ceiling heating cases, the radiant heat flux again had small bands of error

11 and had tendencies similar to those found for total heat flux. The convective heat flux had a much 
larger error band. One of the main reasons for this result may be that the target surfaces benefit less from buoyancy effects, due to their position and operation, resulting in very small values, thus in high percentage errors.

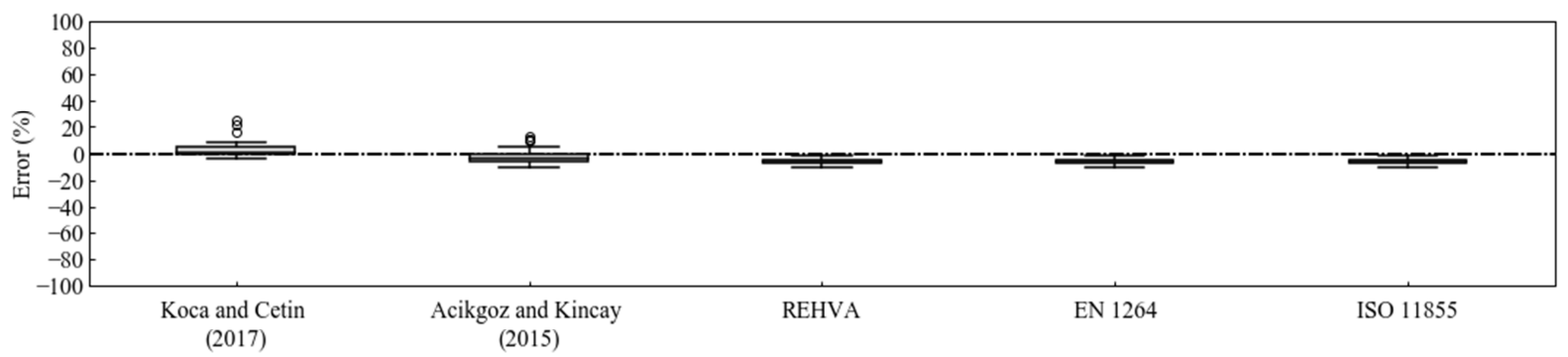

(a) Total Heat Transfer

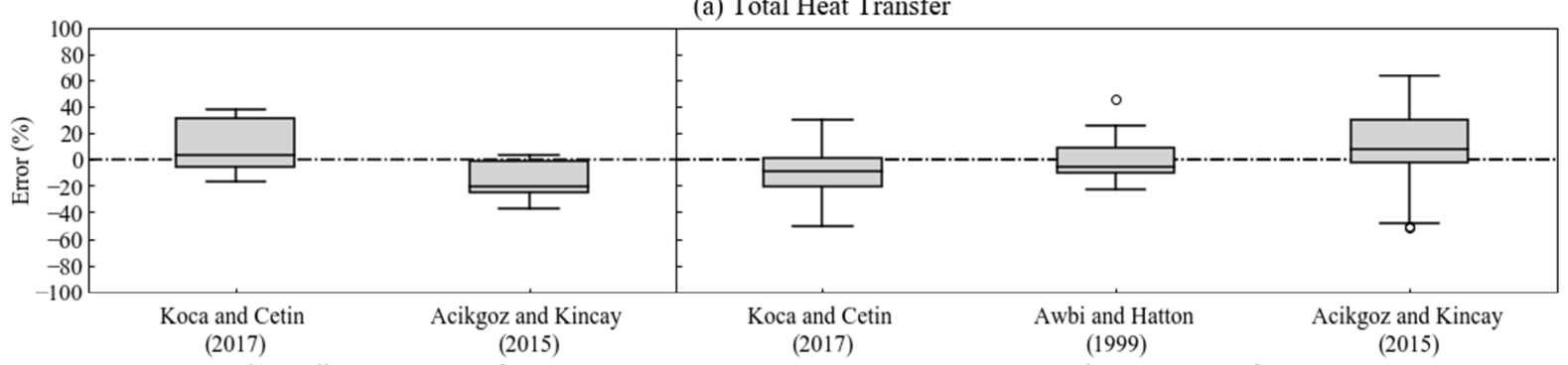

(b) Radiant Heat Transfer

(c) Convective Heat Transfer

Fig. 10 Error between measured and predicted heat flux using the heat transfer coefficients recommended in the literature (wall heating/cooling, $\mathrm{n}=42$ )

Wall heating and cooling conditions resulted in a different pattern compared with other surfaces. Both heating and cooling conditions are included in Fig. 10 since they were not distinguished in standards and guidelines. Unlike what was found for other surfaces, the predicted total heat flux had the least percentage of error, while error bands between $40-60 \%$ were obtained for radiant heat flux. The convective heat flux also showed a large error band, because the convective heat flux measured by Koca and Çetin [17] had a different trend compared with other measurements. 
2 Table 3 lists the measurement and calculation conditions for each experimental study. As shown in

3 the previous section, the measured and recommended values in the literature are inconsistent,

4 requiring further investigation of the measurement and calculation conditions of each experiment.

5 In addition to the dimensions of the test chamber and the radiant surface area, differences or lack of

6 information were seen in the heat flux measurement/calculation method, measurement height of the

7 reference temperature, use of ventilation/air supply, and types of load/heat source.

8 
Table 3. Measurement and calculation condition for each article

\begin{tabular}{|c|c|c|c|c|c|c|c|c|c|c|c|}
\hline \multirow{2}{*}{ Author } & \multirow{2}{*}{$\begin{array}{l}\text { Dimensions } \\
l \times w \times h(\mathrm{~m})\end{array}$} & \multirow{2}{*}{$\begin{array}{c}\text { Radiant Surface } \\
\text { Area }\left(\mathbf{m}^{2}\right)\end{array}$} & \multirow{2}{*}{$\begin{array}{c}\text { Hydraulic } \\
\text { Diameter (m) }\end{array}$} & \multirow{2}{*}{\multicolumn{3}{|c|}{$\begin{array}{cc}\begin{array}{c}\text { Heat Flux Measurement/Calculation Method } \\
\text { Total }\end{array} \text { Radiant } & \text { Convective } \\
\end{array}$}} & \multicolumn{2}{|c|}{ Meas. Height (m) } & \multirow{2}{*}{$\begin{array}{l}\text { Ventilation/ } \\
\text { Air Supply }\end{array}$} & \multicolumn{2}{|c|}{ Load/Heat Source Type } \\
\hline & & & & & & & $T_{o p}$ & $T_{a}$ & & Type & Description \\
\hline Okamoto et al. [9] & $\mathrm{n} / \mathrm{a}$ & $\mathrm{n} / \mathrm{a}$ & $\mathrm{n} / \mathrm{a}$ & $\begin{array}{l}\text { heat flux sensor } \\
\text { on surface }\end{array}$ & $\begin{array}{l}\text { radiant flux } \\
\text { sensor }\end{array}$ & total - radiant & $\mathrm{n} / \mathrm{a}$ & $\mathrm{n} / \mathrm{a}$ & $\mathrm{n} / \mathrm{a}$ & $\mathrm{n} / \mathrm{a}$ & - \\
\hline Yuan et al. [10] & $4.2 \times 3.6 \times 2.4$ & 12 & 3.1 & system side calculation & - & - & - & $\begin{array}{l}0.75,1.5 \\
1.9,2.38\end{array}$ & no & $\begin{array}{l}\text { dummies, } \\
\text { wall/floor surface }\end{array}$ & - \\
\hline Acikgoz and Kincay [11] & $1.8 \times 1.8 \times 2.85$ & 5.1 & 2.2 & system side calculation & $\begin{array}{l}\text { MRT method } \\
\text { calculation }\end{array}$ & total - radiant & - & 1.45 & $\mathrm{n} / \mathrm{a}$ & wall surface & $\begin{array}{l}\text { opposite side of } \\
\text { heated wall }\end{array}$ \\
\hline Zhang et al. [12] & $\begin{array}{l}12 \times 6 \times 3 \\
10.5 \times 6 \times 5\end{array}$ & $\begin{array}{c}26 / 72.8 \\
19.5 / 54.6 \\
\text { (projected / surface) }\end{array}$ & - & system side calculation & $\begin{array}{l}\text { MRT method } \\
\text { calculation }\end{array}$ & total - radiant & 1.5 & 1.5 & $\mathrm{n} / \mathrm{a}$ & external & field measurement \\
\hline Andrés-Chicote et al. [13] & $3.6 \times 3.6 \times 3$ & 4.8 & 2.2 & system side calculation & $\begin{array}{l}\text { MRT method } \\
\text { calculation }\end{array}$ & total - radiant & 1.1 & 1.1 & yes & supply air & - \\
\hline Causone et al. [14] & $4.3 \times 2.7 \times 2.56$ & 11.6 & 3.3 & $\begin{array}{l}\text { system side calculation } \\
\text { - heat loss }\end{array}$ & $\begin{array}{l}\text { MRT method } \\
\text { calculation }\end{array}$ & total - radiant & 1.1 & $\begin{array}{l}0.1,1.1 \\
\quad 1.7\end{array}$ & $\mathrm{n} / \mathrm{a}$ & $\begin{array}{l}\text { metal cylinder* } \\
\text { wall surface** }\end{array}$ & $\begin{array}{l}* \text { cooling case } \\
* * \text { heating case }\end{array}$ \\
\hline Cholewa et al. $[15,16]$ & $1.56 \times 1.56 \times 2.21$ & 2.4 & 1.6 & $\begin{array}{l}\text { heat flux sensor } \\
\text { on surface }\end{array}$ & $\begin{array}{l}\text { MRT method } \\
\text { calculation }\end{array}$ & total - radiant & $0.6,1.1$ & $\begin{array}{l}0.1,0.6 \\
1.1,1.7\end{array}$ & $\mathrm{n} / \mathrm{a}$ & none & $\begin{array}{l}\text { insulated enclosure, } \\
\text { steady state assumed } \\
\text { after } 8-12 \mathrm{~h} \text { from } \\
\text { room setting change }\end{array}$ \\
\hline Koca and Çetin [17] & $4 \times 4 \times 3$ & $6,14.4$ & $2.2,2.4$ & $\begin{array}{l}\text { system side calculation } \\
\text { - heat loss }\end{array}$ & $\begin{array}{l}\text { MRT method } \\
\text { calculation }\end{array}$ & total - radiant & $\mathrm{n} / \mathrm{a}$ & $\mathrm{n} / \mathrm{a}$ & no & external & $\begin{array}{l}\text { surrounding space } \\
\text { conditioned }\end{array}$ \\
\hline Koca et al. [18] & $6 \times 4 \times 3$ & $4.4,11,15.4$ & $2.1,3.1,-$ & $\begin{array}{l}\text { system side calculation } \\
\text { - heat loss }\end{array}$ & $\begin{array}{l}\text { MRT method } \\
\text { calculation }\end{array}$ & total - radiant & 1.1 & 1.1 & no & external & $\begin{array}{l}\text { surrounding space } \\
\text { conditioned }\end{array}$ \\
\hline Yuan et al. [19] & $4.2 \times 3.6 \times 2.4$ & 12 & 3.1 & $\begin{array}{l}\text { system side calculation } \\
\text { - heat loss }\end{array}$ & $\begin{array}{l}\text { MRT method } \\
\text { calculation }\end{array}$ & - & $\mathrm{n} / \mathrm{a}$ & $\begin{array}{l}0.75,1.5 \\
1.9,2.38\end{array}$ & no & $\begin{array}{l}\text { dummies, } \\
\text { wall/floor surface }\end{array}$ & - \\
\hline Miriel et al. [20] & $\mathrm{n} / \mathrm{a}$ & 14 & $\mathrm{n} / \mathrm{a}$ & - & - & $\begin{array}{l}\text { simulation and } \\
\text { measurement } \\
\text { comparison }\end{array}$ & - & $\mathrm{n} / \mathrm{a}$ & $\mathrm{n} / \mathrm{a}$ & external & field measurement \\
\hline Awbi and Hatton [21] & $\begin{array}{c}2.78 \times 2.78 \times 2.3 \\
1.05 \times 1.01 \times 1.05\end{array}$ & 5.9 & 2.4 & $\begin{array}{c}\text { system side calculation } \\
\text { - heat loss }\end{array}$ & $\begin{array}{l}\text { MRT method } \\
\text { calculation }\end{array}$ & total - radiant & - & 1.15 & $\mathrm{n} / \mathrm{a}$ & wall surface & one wall \\
\hline Olesen et al. [23] & $6 \times 4 \times 2.8$ & 24 & 4.8 & $\begin{array}{l}\text { system side calculation } \\
\text { - heat loss }\end{array}$ & $\begin{array}{l}\text { MRT method } \\
\text { calculation }\end{array}$ & total - radiant & $0.6,1.1$ & $0.6,1.1$ & no & external & $\begin{array}{l}\text { surrounding space } \\
\text { conditioned }\end{array}$ \\
\hline Evren et al. [24] & $2.74 \times 2.25 \times 2.45$ & 6.2 & 2.5 & radiant + convective & $\begin{array}{l}\text { MRT method } \\
\text { calculation }\end{array}$ & calculation & $\mathrm{n} / \mathrm{a}$ & $\mathrm{n} / \mathrm{a}$ & $\mathrm{n} / \mathrm{a}$ & wall surface & all walls \\
\hline
\end{tabular}

System side calculation: calculated from water inlet/outlet temperature and flow rate

MRT method calculation: calculated from surface temperature of the radiant surface and other surfaces within the room 
4.1 Calculation Method of Heat Transfer

In most cases, radiant heat flux was estimated by numerical calculation using the surface emissivity and temperature of each surface within the room. The values were similar in each article, but when Okamoto et al. [9] used a radiant flux meter to measure the radiation from the cooled/heated surface, they obtained a higher heat transfer coefficient for the cases using spiral pipe panels.

The total heat flux is obtained either by system-side calculation using inlet and outlet water temperatures and the flow rate of the radiant system or by measuring emission from the surface with heat flux sensors. In the articles reviewed in the present study, the former approach was more commonly taken. However, Cholewa et al. $[15,16]$ argues that the latter approach should be taken, since calculations based on the radiant system input and outputs do not necessarily represent the heat flux towards the room. Heat loss to or heat gain from the other side of the heated/cooled surface or the edges of the surface is inevitable. Some articles indicate that heat loss was taken into account in the calculation; however, the method used to calculate heat loss was not specified in most cases. Measuring the total emission from the surface, on the other hand, has its own drawbacks. When measuring the heat flux from a surface, it must be noted that the measured value only represents the heat transfer at the point it is placed, so the ability of the measured value to represent the total heat transfer must be considered. In addition, contact sensors such as heat flux sensors or surface temperature sensors change the surface conditions and temperature of the measurement point in which they are placed, which is another possible source of error. Obtaining a good contact between the sensor and the surface is also a common measurement problem. A possible alternative for surface temperature measurements may be infrared sensors, although an assumption of emissivity is necessary.

All the articles reporting an experimental approach obtained the convective heat flux from the difference between the total and radiant heat flux, the one exception being Evren et al. [24], who 
used the ASHRAE formula to calculate the convective heat flux from the measured temperatures. As previously stated, radiant heat flux showed little deviation between the different studies, so the errors in the total heat flux value are likely to originate from the convective heat flux. The convective heat flux is obtained by the difference between the total and radiant heat flux, and therefore both the variation in the convection phenomenon and experimental errors will be allocated in its value. Since the convective heat flux has smaller values compared to the total heat flux, the deviation will be larger when converted to heat transfer coefficients. The implementation of such values will thus result in relatively larger percentages of error, which was most prominent in the floor cooling and ceiling heating cases.

It should be noted that since one source of error is in the calculation process used to obtain the total and convective heat flux, the prediction accuracy shown in Figs. 6-10 does not necessarily represent the effectiveness of each value or expression, but shows their prediction (under- or overprediction) tendency in the currently available dataset. When small bands of error are seen for all predictions in one type of heat flux (e.g. radiant heat flux), the current recommendations may be assumed to be reliable and the impact of its choice to be minimal. In cases of a wider range of error, the choice of the heat transfer coefficient will have a greater impact on the predicted heat flux. In this case, either a re-examination of the calculation and measurement process or the use of other parameters, or both, may be necessary. The small band of error in the radiant heat transfer may also be the result of all the investigations (except one) applying the same method, in which case a more innovative method or equipment for the measurement of relevant parameters such as surface temperature and emissivity may need to be considered.

\subsection{Reference Temperature}

The selection of the reference temperature is one of the determining factors of heat transfer coefficients since they do not represent the actual heat transfer phenomena. For instance, the radiant 
heat transfer coefficient is a simplification of the heat transfer between the target surface and all other surrounding surfaces. Similarly, the convective heat transfer coefficient often uses the average air temperature of the room while the actual heat transfer takes place between a surface and the boundary layer. The choice and position of the reference temperature must therefore be identified when using heat transfer coefficients.

(1)

Olesen et al. [23] performed multiple calculations using the same convective and total heat flux with different reference temperatures, to demonstrate the effect of its choice for floor cooling conditions. They suggested that the reference temperature should be chosen according to the purpose of the heat transfer coefficients; for instance, when calculating the maximum capacity based on comfort conditions, the operative temperature at 0.6 and $1.1 \mathrm{~m}$ above the floor should be used for a sedentary and standing person, respectively. Subsequent studies also compared heat transfer coefficients based on the reference temperature measurement height for convective and total heat flux and resulted in different heat transfer coefficients for each height [14-16]. However, only 5 of 14 studies in Table 3 measured the reference temperatures at the height of 0.6 or $1.1 \mathrm{~m}$, and others selected different heights or did not specify them. When using heat transfer coefficients for simulations that assume a "well-mixed" air distribution, the choice of reference temperature in measurements and simulations should depend on which would most closely represent the operational conditions.

\subsection{Temperature Stratification and Ventilation}

As previously stated, the choice of reference temperature and its measurement height altered the outcome of the total and convective heat transfer coefficients. In other words, there was a temperature stratification during the measurements. Yuan et al. [10, 19] and Olesen et al. [23] clearly stated that no ventilation or air supply was used, in order to minimize forced convection on the cooled/heated surface. On the other hand, Andrés-Chicote et al. [13] supplied air to their test 
chambers to obtain a uniform environment, taking precautions to keep the air velocity within the room at a low value. Other articles included in the present review did not specify whether or not such systems were used.

Although the convective heat transfer in the articles reviewed here mainly focused on natural convection, the measurement height and position are also important for mixed convection. Spitler et al. [29] conducted an experiment in an isothermal test chamber with different ventilation flow rates and examined the interior convective heat transfer coefficients (though not specifically for radiant systems). As a reference temperature, the return air temperature, average air temperature of the entire room, air temperature adjacent to the observed surface, and the average air temperature at the height of the observed surface (for walls) were compared. In high ventilation flow rates where forced convection was dominant, the differences caused by the choice of reference temperature were minimal. However, in low ventilation flow rates, in which mixed convection took place, deviations were seen due to temperature stratification.

Introducing air movements to rooms will strongly affect the indoor environment in terms of temperature stratification and air velocity. The optimal choice of reference temperature measurement height and position will also be affected, especially at low ventilation flow rates. As previous studies [30] have indicated, increased air velocity will result in a higher heating/cooling capacity of the radiant system, due to the effect of forced convection. There is most likely a trade-off between temperature uniformity and air velocity in this case. However, the effect of different ventilation strategies on heat transfer from the cooled/heated surface should be examined as it more closely represents real-life conditions. Other knowledge gaps include infiltration, inter-zone air movement (such as by open doors), and the transient conditions of the room caused by the movement of people. 


\subsection{Room Dimensions}

The correlations for the convective heat transfer in Tables 1, 2 show that in addition to the temperature difference, the hydraulic diameter or wall height (i.e. dimensions of the room and cooled/ heated surface) were used as parameters. As listed in Table 3, the dimensions of each test chamber and the surface area of the controlled surface were different, resulting in inconsistencies between different studies. The calculated hydraulic diameters varied between 1.6-3.4 $\mathrm{m}$. In the measurements plotted in Fig. 1, for instance, the lowest and highest values were obtained in the test chambers used by Cholewa et al. [15, 16] and Yuan et al. [10, 19], respectively. When using the detailed calculation suggested by ASHRAE [8], the differences in the hydraulic diameters between the two chambers resulted in an error of about $1 \mathrm{~W} /\left(\mathrm{m}^{2} \cdot \mathrm{K}\right)$ at $\Delta T=8 \mathrm{~K}$ in the convective heat transfer coefficient (for ceiling cooling cases). A smaller hydraulic diameter will result in a larger temperature dependency, and a more stable convective heat transfer coefficient will be obtained with a larger hydraulic diameter. This relationship was observed in the two articles reviewed, as previously stated $[10,15]$.

Except for very large spaces, ASHRAE [8] recommends that simplified expressions should be used to calculate the convective heat flux, as shown in Table 1, under the assumption that the effect of room size is negligible. In the simplified expression, a hydraulic diameter of $4.91 \mathrm{~m}$ is used, which is larger than any of the test chambers listed in Table 3. A rough estimation of the Rayleigh number based on the hydraulic diameter and air temperature of these studies resulted in a range between $3 \times 10^{8}-6 \times 10^{10}$, indicating that all the cases studied fall in the turbulent flow regime. However, the air temperature available in the literature represents the whole room or a certain height instead of the boundary layer, therefore it is not an accurate calculation and was thus excluded from the table. The effect of small enclosures and the limitation it poses on the heat transfer coefficient should be further studied and clarified. 


\subsection{Types of Load/Heat Source}

Different types of load/heat sources were used in each of the measurements listed in Table 3. Measurements simulating external loads controlled the temperature of adjacent spaces and thus controlled the surface temperature of the inner surface of the test chamber (and also had a certain effect on air temperature by infiltration). Others had pipes embedded in the walls and floors to directly adjust the surface temperatures. Metal cylinders (heated dummies) were used to represent occupants in some studies. In general, the heat load of a surface mostly accounts for radiant heat gain, while internal loads such as metal cylinders representing occupants have a higher percentage of convective heat gain. As an alternative approach, Andrés-Chicote et al. [13] used supply air as a heat source, while Cholewa et al. $[15,16]$ had no heat sources apart from the radiant system, assuming steady state after 8-12 hours of setting the water inlet temperature and flow rate.

Several studies of the effects of heat load types on the thermal behavior of radiant systems have been published. Novoselac et al. [31] compared the convective heat transfer coefficient of a cooled ceiling surface when there were two different heat sources: a heated surface simulating a window, and a convective heat source (a perforated box containing light bulbs, placed within a case covered with aluminum foil). They found that the natural convective heat transfer coefficient (with the reference temperature being the air temperature measured just below the cooled ceiling) was larger for the convective heat source, as a result of the buoyant plume. Niu et al. [32] conducted a simulation and an experiment comparing the effects of internal heat sources (such as people and equipment) and surface heat sources (both single and multiple surfaces) on the cooling capacity of a cooled ceiling. Their results showed that the cooling capacity of the cooled ceiling was higher when the heat load was a heated surface. Mustakallio et al. [33] experimentally compared internal and surface heat loads in terms of the heat transfer coefficient between the mean water temperature of the radiant ceiling panel system and room air temperature and obtained a similar trend. These studies indicate that the radiant/convective proportion of the heat source greatly influences the 
thermal output of radiant systems. The convective portion also contributes to the temperature stratification in the room, another important factor that influences the performance of radiant systems, as discussed in the previous section.

As previously stated, buoyancy effects differ according to the position of the cooled/heated surface. Current standards assume that this effect is similar for ceiling cooling and floor heating. However, since convection from other heat sources affects the performance of radiant systems, it is possible that the difference in the positional relationship between the radiant surface and the heat source may result in different heat transfer coefficients for ceiling cooling and floor heating.

\section{Conclusions}

An in-depth review of the surface heat transfer coefficients of radiant systems was conducted. Recommended values, expressions and measurement results in standards, guidelines and published articles were comprehensively studied. There were many discrepancies between the different studies, which are likely to have been caused by the use of different measurement conditions and methods (i.e., calculation methods of heat transfer, reference temperature, temperature stratification, use of ventilation, room and surface dimensions, and load types). In order to be able to select the appropriate heat transfer coefficient, the purpose and use of it must be identified, and this is commonly overlooked. Heat transfer coefficients are simplified representations of the complex heat transfer actually taking place, and the simplification process must take account of the relevant parameters (reference temperatures and measurement conditions) and choose those that are suitable for the purposes of that specific application.

Heat transfer coefficients are often used for load calculations and building simulations. For general calculation such as load calculations (heat emission to or removal from a space), total heat transfer coefficients with operative temperature as the reference, as suggested in standards and guidelines, 
are suitable for estimating the load for a given comfort criterion. In building simulations where more detailed and dynamic calculations are necessary, convective and radiant (if the MRT calculation is not adopted) heat transfer coefficients would be used. As shown in the comparison of various studies, the use of $5.5 \mathrm{~W} /\left(\mathrm{m}^{2} \cdot \mathrm{K}\right)$ as a radiant heat transfer coefficient would be a safe assumption, which yields errors caused by uncertainties in emissivity of less than 4\% [23]. The selection of a valid convective heat transfer coefficient still requires further research. At present, the most valid option is to use a convective heat transfer coefficient that was obtained under measurement conditions that most closely represents the condition (room and surface dimensions, temperature range, etc.) in which the system will be used. A general formulation that takes into account the different measurement conditions and methods discussed in this paper will further be necessary. Raw data and crucial parameters such as the reference temperature measurement height and heat loss/gain calculation method are missing in many studies, which implies that the present studies lack the perspective of providing sufficient information to select the appropriate environment that most closely matches the intended application.

Since the measurement conditions have a large impact on the value of the heat transfer coefficients, future studies should focus on investigating the reasons for the differences between heat transfer coefficient values obtained under different measurement conditions. Most of the studies reviewed in this article were carried out in well-controlled conditions similar to that of standard cooling capacity measurements. Further experiments should consider more realistic conditions, such as combinations of different ventilation systems and load types. In addition, the effects of the difference in heat transfer coefficients on the resulting indoor environmental conditions and on the dimensioning of the mechanical system should be evaluated in simulation studies in order to determine the uncertainty range of the calculated heat flux. 
Acknowledgements

The first author would like to thank Japan Society for the Promotion of Science (JSPS) for financial support. The authors thank Prof. David P. Wyon for his comments and help in editing the manuscript of this article.

\section{References}

1. K.-N. Rhee and K.W. Kim, A 50 year review of basic and applied research in radiant heating and cooling systems for the built environment. Building and Environment, 91, 166-190 (2015)

2. A.-J. N. Khalifa, Natural convective heat transfer coefficient - a review I. Isolated vertical and horizontal surfaces. Energy Conversion and Management, 42, 491-504 (2001)

3. A.-J. N. Khalifa, Natural convective heat transfer coefficient - a review: II. Surfaces in twoand three-dimensional enclosures. Energy Conversion and Management, 42(4), 505-517 (2001)

4. J. Babiak, B.W. Olesen, D. Petráš, Low temperature heating and high temperature cooling, REHVA Guidebook no. 7. (2009)

5. EN1264-5 Water based surface embedded heating and cooling systems - Part 5: Heating and cooling surfaces embedded in floors, ceilings and walls - Determination of the thermal output, CEN (2008)

6. EN15377-1 Heating systems in buildings - Design of embedded water based surface heating and cooling systems - Part 1: Determination of the design heating and cooling capacity, CEN (2008)

7. ISO11855-2 Building environment design - Design, dimensioning, installation and control of embedded radiant heating and cooling systems - Part 2: Determination of the design heating and cooling capacity, International Organization for Standardization (2012)

8. ASHRAE, ASHRAE Handbook - HVAC Systems and Equipment, (2012)

9. S. Okamoto, H. Kitora, H. Yamaguchi, T. Oka, A simplified calculation method for estimating heat flux from ceiling radiant panels. Energy and Buildings, 42(1), 29-33 (2010) 
10. Y. Yuan, X. Zhang, X. Zhou, J. Gao, An experiment-oriented simulation method for cooling capacity determination of cooling ceiling radiant panel system. Science and Technology for the Built Environment, 22(6), 831-844 (2016)

11. O. Acikgoz, O. Kincay, Experimental and numerical investigation of the correlation between radiative and convective heat-transfer coefficients at the cooled wall of a real-sized room. Energy and Buildings, 108, 257-266 (2015)

12. L. Zhang, X.-H. Liu, Y. Jiang, Experimental evaluation of a suspended metal ceiling radiant panel with inclined fins. Energy and Buildings, 62, 522-529. (2013)

13. M. Andrés-Chicote, A. Tejero-González, E. Velasco-Gómez, F. J. Rey-Martínez, Experimental study on the cooling capacity of a radiant cooled ceiling system. Energy and Buildings, 54, 207-214 (2012)

14. F. Causone, S. P. Corgnati, M. Filippi, B.W. Olesen, Experimental evaluation of heat transfer coefficients between radiant ceiling and room. Energy and Buildings, 41(6), 622-628 (2009)

15. T. Cholewa, R. Anasiewicz, A. Siuta-Olcha, M. A. Skwarczynski, On the heat transfer coefficients between heated/cooled radiant ceiling and room. Applied Thermal Engineering, $117,76-84(2017)$

16. T. Cholewa, M. Rosiński, Z. Spik, M. R. Dudzińska, A. Siuta-Olcha, On the heat transfer coefficients between heated/cooled radiant floor and room. Energy and Buildings, 66, 599-606 (2013)

17. A. Koca, G. Çetin, Experimental investigation on the heat transfer coefficients of radiant heating systems: Wall, ceiling and wall-ceiling integration. Energy and Buildings, 148, 311-326 (2017)

18. A. Koca, Z. Gemici, Y. Topacoglu, G. Çetin, R. C. Acet, B. B. Kanbur, Experimental investigation of heat transfer coefficients between hydronic radiant heated wall and room. Energy and Buildings, 82, 211-221 (2014) 
19. Y. Yuan, X. Zhang, X. Zhou, Simplified correlations for heat transfer coefficient and heat flux density of radiant ceiling panels. Science and Technology for the Built Environment, 23(2), 251-263 (2017)

20. J. Miriel, L. Serres, A. Trombe, Radiant ceiling panel heating-cooling systems: experimental and simulated study of the performances, thermal comfort and energy consumptions. Applied Thermal Engineering, 22(16), 1861-1873 (2002)

21. H. B. Awbi, A. Hatton, Natural convection from heated room surfaces. Energy and Buildings, 30(3), 233-244 (1999)

22. R. Karada $\breve{g}$, New approach relevant to total heat transfer coefficient including the effect of radiation and convection at the ceiling in a cooled ceiling room. Applied Thermal Engineering, 29(8), 1561-1565 (2009)

23. B. W. Olesen, E. Michel, F. Bonnefoi, M. De Carli, Heat exchange coefficient between floor surface and space by floor cooling - theory or a question of definition, ASHRAE Transactions, 106, 684-694 (2000).

24. M. F. Evren, A. Özsunar, A. Biyikoglu, B. Kilkis, Determination of heat transfer coefficient between heated floor and space using the principles of ANSI/ASHRAE standard 138 test chamber, ASHRAE Transactions, 123, 71-81 (2017)

25. T. C. Min, L. F. Schutrum, G. V. Parmelee, J. D. Vouris, Natural convection and radiation in a panel heated room, ASHRAE Transactions, 62, 337-358 (1956)

26. R. Karadağ, The investigation of relation between radiative and convective heat transfer coefficients at the ceiling in a cooled ceiling room. Energy Conversion and Management, 50(1), $1-5(2009)$

27. O. Acikgoz, A novel evaluation regarding the influence of surface emissivity on radiative and total heat transfer coefficients in radiant heating systems by means of theoretical and numerical methods. Energy and Buildings, 102, 105-116 (2015) 
28. ISO 7730 Ergonomics of the thermal environment - Analytical determination and interpretation of thermal comfort using calculation of the PMV and PPD indices and local thermal comfort criteria, International Organization for Standardization (2005)

29. J. D. Spitler, C. O. Pedersen, D. E. Fisher, Interior convective heat transfer in buildings with large ventilative flow rates. ASHRAE Transactions, 97, 505-515 (1991)

30. J.-W. Jeong, S. A. Mumma, Ceiling radiant cooling panel capacity enhanced by mixed convection in mechanically ventilated spaces. Applied Thermal Engineering, 23, 2293-2306 (2003)

31. X. Niu, Z. Tian, B. Duan, Z. Wang, Influences of heat source forms on the cooling capacity of the radiant cooling terminal. Energy and Buildings, 72, 102-111 (2014)

32. P. Mustakallio, R. Kosonen, A. Melikov, The effects of mixing air distribution and heat load arrangement on the performance of ceiling radiant panels under cooling mode operation. Science and Technology for the Built Environment, 23(7), 1090-1104 (2017)

33. A. Novoselac, B. J. Burley, J. Srebric, New Convection Correlations for Cooled Ceiling Panels in Room with Mixed and Stratified Airflow. HVAC\&R Research, 12(2), 279-294 (2006) 
Highlights

- Surface heat transfer coefficients are critical parameters for designing and evaluating performance of radiant systems.

- A literature review was conducted for the surface heat transfer coefficients of radiant systems.

- Measured heat transfer and the prediction accuracy of suggested heat transfer coefficients were compared.

- Measurement conditions and calculation methods were identified to be potential causes of discrepancies.

- Suggestions were made for future studies and how to select the appropriate heat transfer coefficient from literature. 